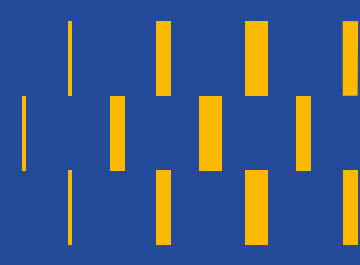

\title{
Mitos y rituales en torno al agua en la comunidad andina de Cullhuay: de La Viuda al cambio global
}

\section{Myths and rituals around water in the andean community of Cullhuay: from La Viuda to global change}

\author{
María Nilda Varas Castrillo ${ }^{1}$ (D) https://orcid.org/0000-0003-3397-8921 \\ José María Valcuende del Río ${ }^{2}$ (D) https://orcid.org/0000-0003-1161-2611 \\ ${ }^{1}$ Universidad Nacional Agraria de La Molina, Lima, PERÚ. Email: nvaras@lamolina.edu.pe \\ ${ }^{2}$ Universidad Pablo de Olavide, Sevilla, ESPAÑA. Email: jmvalrio@upo.es
}

\section{Resumen}

El análisis de los mitos y rituales nos ayuda a comprender la significación que adquiere el agua para las poblaciones locales andinas, en un contexto marcado por transformaciones socioambientales profundas. En este texto nos interesa analizar algunos de los mitos y rituales de la comunidad andina de Cullhuay, que integra -como parte de la comunidad-al agua en sus múltiples formas, y cuya importancia trasciende el valor meramente monetario. Esta concepción se confronta con los discursos tecnocráticos que imponen nuevas narrativas y, con ello, nuevas formas de gestión a partir de las cuales se legitima la expropiación discursiva y material de este recurso central para la reproducción material e ideática de la comunidad.

Palabras clave: mitos, rituales, Champería, discursos, imaginarios.

\begin{abstract}
The analysis of myths and rituals helps us understand the meaning that water acquires for local Andean populations in a context shaped by profound socio-environmental transformations. In this text we are interested in analyzing some of the myths and rituals related to water in the Andean community of Cullhuay, integrated -as part of the community- to water in its multiple forms, and whose importance transcends the merely monetary value. This understanding clashes with the technocratic discourses which impose new narratives, and with it, new forms of management from which the discursive and material expropriation of this central resource is legitimized for the material and ideatic reproduction of the community.
\end{abstract}

Keywords: myths, rituals, Champeria, discourses, imaginary.

Recibido: 3 septiembre 2019. Aceptado: 14 octubre 2019 


\section{Introducción}

Los mitos y rituales en torno al agua en las comunidades de los Andes ponen en evidencia la centralidad de este recurso en la cosmovisión andina (Sherbondy, 1995). En este artículo se analizará la significación de algunos de estos mitos y rituales en la comunidad de Culhuay, situada en los Andes centrales peruanos. Las transformaciones experimentadas por esta población se han traducido en la incorporación de prácticas y discursos vinculados con el discurso científico-tecnocrático -el cual adquiere un papel relevante en la gestión del agua- y que se confrontan con las narrativas y acciones simbólicas tradicionales. Si el agua ha sido para los comuneros de Culhuay un elemento central, a partir del cual se articula la comunidad, para los funcionarios de los organismos del Estado el territorio de la comunidad de Cullhuay es un mero repositorio de un recurso abundante que debe ser rentabilizado para abastecer a otras poblaciones (a los agricultores de la cuenca media y baja, así como a otros centros poblados, especialmente a Lima). El agua pasa a ser reconocida como un recurso global que trasciende el espacio local, desde el cual se ha gestionado tradicionalmente. De esta forma, los actores locales que ocuparon una posición central pasan a un plano secundario en la toma de decisiones. Esto implica un cambio en las posiciones de los diferentes agentes, justificado en nuevas narrativas tecnocientíficas que resignifican los recursos en un proceso de expropiación discursiva, que es también una expropiación material.

Los discursos científico-tecnocráticos se aproximan a los mitos y rituales andinos en torno al agua como meras supervivencias folclóricas, consideradas intrascendentes a la hora de rentabilizar un recurso que es entendido fundamentalmente en clave económica (Bolados y Babidge, 2016). Pero este fenómeno no es exclusivo de esta comunidad; de hecho, son diversas las investigaciones realizadas en el Perú que muestran las contradictorias perspectivas y discursos en el manejo y gestión de los recursos entre, por un lado, las comunidades campesinas o indígenas y, por otro, los funcionarios y los técnicos estatales (Gelles, 1984, 1995; Guillet, 1995; Carey, 2014). Y es que son diferentes las formas de gestionar y entender los recursos tanto por parte de los funcionarios estatales como por las poblaciones locales: "el uno toma una perspectiva secular, 'racional' y burocrática de la administración del agua, mientras que el otro se enfoca en asegurar ritualmente el agua, lo cual es visto como parte de un universo social y simbólico mayor" (Gelles, 1995, p. 394).

El discurso tecnocientífico, pues, modifica el significado del espacio local, lo desterritorializa al mismo tiempo que resignifica el agua y los recursos, transformando a las comunidades locales en actores secundarios. Racionalidad y desarrollo sustentan la lógica de una naturaleza que es interpretada, desde las lógicas que respectivamente Pálsson (1996) definiera como paternalista y orientalista, ya sea como objeto de explotación, bien como objeto de protección. Ambas lógicas, a pesar de sus diferencias, tienen un mismo denominador común: la superposición jerárquica de los expertos sobre la población no experta y la de los seres humanos sobre los no humanos. Los componentes no humanos del medio pasan a ser considerados objetos (ya sean objetos de explotación, ya de protección). Una objetivación que se contrapone a las perspectivas andinas, que presuponen agencia a todos los elementos que componen su ecosistema. ${ }^{1}$ Sin embargo, la visión occidental sobre la naturaleza no está exenta de mitos, que se sustentan en el dualismo cultura-naturaleza y en una posición antropocéntrica. ${ }^{2}$

1 Rappaport define el ecosistema como "el total de organismos vivientes y substancias no vivientes ligados por intercambios materiales dentro de una porción definida de la biosfera” $(1987,262)$.

2 Autores como Descola han profundizado en la dualidad cultura/naturaleza a partir de la que se ordena 
La cosificación de los recursos naturales convierte en intranscendentes los elementos no cuantificables, los aspectos emocionales e identitarios a partir de los que los humanos crean relaciones con el medio y los recursos. "La conservación ambiental solo será posible cuando, al igual que los mitos, logre construir una relación con lo natural que signifique y emocione a las personas y donde la naturaleza se transforme en un verdadero elemento de identidad" (Durand, 2005, p. 215). Como ya seńalara Rappaport, los rituales juegan un papel central en cuanto a comprender las vinculaciones que se establecen en lo que hoy denominamos socioecosistemas, contribuyendo a regular las relaciones socioambientales: "[...] el ritual actúa de mediador en las críticas relaciones entre una congregación y las entidades exteriores a ella" (Rappaport, 1987, pp. 3-4). No son fruto de la casualidad (Durkheim, 1982), ni tampoco, como desde el pensamiento tecnocrático se presupone, meras supersticiones que es preciso superar.

Hoy, de forma progresiva, se tiende a poner en valor esos conocimientos locales a los que se les reconoce un carácter "práctico" (Coca y Quintero, 2006; Coca, 2008), en cuanto que son el resultado, en muchos casos, de largas interacciones de coadaptación con el entorno. Y es que, como señala Arce, es fundamental "[...] comprender cómo estas poblaciones locales viven, perciben, sienten el proceso y en lo posible rescatar sus conocimientos y prácticas para desarrollar planes y proyectos de mitigación y de adaptación al cambio climático global" (Arce, 2011, p. 36).

Pero no solamente el análisis de los mitos y rituales adquiere un papel importante desde el punto de vista pragmático (Durkheim, 1982), pues su conocimiento ha contribuido a cuestionar (desde una visión naturalista) la concepción homogeneizadora de lo que, en Occidente, denominamos naturaleza. Los diferentes relatos que se ponen en acción a la hora de interpretar las vinculaciones que se establecen entre los humanos y los no humanos nos aproximan a la existencia de los diversos mundos que conforman, tal y como nos recuerda Escobar (2014), el pluriverso, y con ello la diversidad cultural que sostiene una biodiversidad amenazada por la conversión de la naturaleza en un mero recurso económico. Este hecho adquiere un carácter especialmente dramático en el caso de la gestión de un recurso básico, como lo es el agua. Desde las visiones andinas que responden, siguiendo a Descola $(2005,2009,2011)$, a las ontologías analógicas:

Los humanos y los no humanos pertenecen a una misma colectividad, el mundo, cuya organización interna y cuyas propiedades derivan de las analogías perceptibles entre los existentes. En lenguaje antropológico, podremos hablar aquí de cosmocentrismo, en contraste con el cosmomorfismo del totemismo australiano y el antropocentrismo del animismo.

Sin embargo, las representaciones ontológicas no son inmutables. Las comunidades andinas son, a su vez, realidades dinámicas que han experimentado profundos cambios y son también resignificadas tanto en viejas como en nuevas narraciones y acciones simbólicas. La pregunta que se plantea, llegados a este punto, es qué papel juegan hoy los mitos y rituales tradicionales. Se parte de la hipótesis de que los cambios en los usos del territorio -forzados desde una dinámica

y construye el mundo en las sociedades occidentales. Una idea que ya está presente en Rappaport, que nos recuerda también el carácter mítico de las representaciones occidentales y la necesidad de superar estas dicotomías: "A Rappaport no le interesa la discusión del carácter cualitativamente distinto de la cultura en relación a la naturaleza [...]. De hecho, pretende sobrepasar lo que él entiende como un falso dualismo. Un dualismo que considera que está fuertemente imbuido de un pensamiento religioso que sitúa a los seres humanos por encima de otros seres, sólo un escalón por debajo de los ángeles” (Valcuende, 2003, p. 69). 
global y nacional- implican una readecuación discursiva y ritual que permite la reapropiación del territorio y los recursos. Tal y como plantean Choque y Pizarro en el caso de los comuneros aymaras de Socoroma, en el norte de Chile: "La existencia de continuidades y rupturas en las expresiones rituales son el resultado del cambio cultural, cuyas consecuencias se expresan en la reinterpretación de la identidad y del propio espacio sagrado de los habitantes de esta comunidad" (2013, p. 56).

Efectivamente, lo que se entiende como plano cultural, aunque en este caso prefiramos utilizar el término socioambiental, juega un papel importante, más aún partiendo de una narrativa de la comunidad que integra otros componentes no humanos. De hecho, el caso analizado por Choque y Pizarro (2013) es un buen ejemplo de cómo cambios "naturales" (en ese caso una sequía) pueden provocar cambios culturales y la reactivación de los rituales tradicionales. La modificación de los elementos no humanos con los que se interactúa supone, en último término, una transformación de la comunidad, lo que implica a su vez una modificación en los discursos y prácticas comunitarios.

La aproximación a los mitos y rituales vinculados con el agua en la comunidad de Cullhuay nos permitirá comprender la imbricación (cuando no la confrontación) de los discursos científicotécnicos, por un lado, y de los mitos y ritos tradicionales, por otro. Una confrontación de discursos y prácticas que es también una colisión de intereses que pugnan por la legitimidad en torno a la gestión del agua. Y es que la superposición de discursos y prácticas evidencia la existencia de conflictos y tensiones entre las nuevas políticas del agua y las comunidades locales (Bolados y Babidge, 2017). En este contexto, los mitos y rituales contribuyen a la reapropiación de los recursos, cuando no a la contestación, por parte de los actores locales, de las lógicas foráneas, tal y como ponen de manifiesto diversas investigaciones en otros contextos (Bolados y Babidge, 2017).

Para realizar este abordaje se propone una aproximación etnográfica. Sin duda, la etnografía es una de las más potentes herramientas metodológicas para aprehender las interacciones de la población local con el medio, ya que permite abordar la realidad no solo desde los discursos, sino también desde unas vivencias que son compartidas por el propio investigador en el terreno. Para ello, se realizó trabajo de campo entre los ańos 2011 y 2015, con algunas otras estancias esporádicas entre 2016 y 2018, período en el que se redactaron los resultados de la investigación. Durante ese tiempo se llevó a cabo la observación participante y directa, tanto en la vida cotidiana como en los contextos festivo-ceremoniales. Se realizaron 30 entrevistas en profundidad a varones y mujeres: comuneros, pastores, funcionarios públicos, docentes, dirigentes comunales, etcétera.

Junto a las entrevistas realizadas en Cullhuay, Canta y Lima, donde hoy vive una parte de la población, se realizaron diversos recorridos con otros comuneros por la parte alta para conocer las estancias de los criadores de ganado alrededor del glaciar y el represamiento en las lagunas Chuchún, Leoncocha y Siete Colores. Esta aproximación nos permitió in situ compartir la mirada de nuestros informantes, que interpretaron el paisaje desde sus propias perspectivas.

Se revisaron fuentes secundarias relacionadas con la comunidad y el proceso de desglaciación, así como los proyectos de infraestructura hidráulica y de transporte. Recurrimos, asimismo, a las fuentes documentales de la Autoridad Nacional del Agua (ANA), de Provías (Ministerio de Transporte), de la oficina de Canta del Gobierno Regional; esta documentación fue fundamental para abordar la lógica tecnocrática. 


\section{La comunidad como realidad socioambiental}

No se puede comprender la significación del agua para las poblaciones andinas sin abordar previamente la significación de "lo comunal". Montesinos y Campanera (2017, p. 210) entienden 'lo común' "como una praxis política dinámica dentro de un marco histórico [...] una obligación recíproca de actuar de acuerdo con las normas de una colectividad política, fundamentándose en la participación en una actividad o tarea”.

Dicha praxis tiene como objetivo gestionar unos recursos compartidos, con independencia de que los beneficios puedan repartirse de forma más o menos desigual. ${ }^{3}$ En todo caso prima la acción y las obligaciones colectivas sobre las individuales; no obstante, se evidencia una inevitable tensión existente entre ambos polos (Diez, 2012, 2017; Montesinos y Campanera, 2017).

El análisis de "los bienes comunes", que nunca perdió vigencia en el mundo andino, ha adquirido nuevamente gran importancia desde las perspectivas que cuestionan las lógicas desintegradoras del mercado (Bauman, 2003; Hardt y Negri, 2011; Ostrom, 2011; Bollier y Helfricht, 2013; Mattei, 2013; Laval y Dardot, 2014; Urrutia, Remy y Burneo, 2019). Coinciden Belotti (2014) y Ruiz-Ballesteros (2012) en resaltar que la propiedad, el uso y manejo de los bienes comunes tienen componentes éticos. El deterioro ambiental que experimenta el planeta ha puesto en evidencia las consecuencias de la mercantilización de algunos recursos básicos, lo que se ha traducido también en un movimiento de contestación que tiene su base en la reivindicación del cuidado colectivo de los "bienes comunes"; una réplica social que implica, a su vez, la búsqueda de formas de participación de los ciudadanos en su cuidado y producción; un aspecto que incide en la centralidad de "lo comunitario" para la conservación ambiental (Agrawal, 1997). No es extraño, tal y como analiza Subirats (2013), que los estudios sobre la comunidad, en general, y los bienes comunes, en particular, tengan una larga tradición en las ciencias sociales "periféricas" del Sur global, como tampoco es casual el resurgimiento de los estudios comunitarios en otros contextos culturales, que vuelven a mirar al mundo andino, donde la comunidad sigue siendo una realidad palpable.

Desde la experiencia andina de comunidad ("el común”), las dimensiones socio ecológica y ética están estrechamente relacionadas. La comunidad es un contexto de relaciones, tanto entre humanos como entre estos y su entorno biofísico, imbuidas de vínculos morales recíprocos (Varas, 2017, p. 33).

Efectivamente, la comunidad ha sido, y en cierta medida continúa siendo, la base de las formas de organización sociopolítica a partir de la que se establecía y establece el orden socioambiental en el mundo andino (Arguedas, 1986). ${ }^{4}$ La comunidad andina lo es en la medida que integra también elementos abióticos, biológicos y espirituales, que interactúan entre sí y con los propios humanos. La comunidad, como hemos señalado, es una praxis, pero también una forma de organización con un fuerte componente identitario y emocional, que contribuye a reforzar

3 La comunidad no es ni mucho menos una realidad unitaria ni está exenta de relaciones de poder; por otro lado, encontramos diversos tipos de comunidades, en lo que no podemos detenernos. Para un análisis en profundidad, Diez ( 2012 y 2017).

4 No vamos a entrar en el debate sobre el origen de la comunidad andina, ahora bien, compartimos con Arguedas (1986) que esta institución se conforma a partir del orden impuesto por la administración colonial, integrando en la institución corporativa edil, a nivel de aldea campesina colectivamente sometida a tributo, elementos territoriales anteriores a la invasión, que permanecen. 
los lazos entre sus diferentes componentes y a naturalizar derechos y obligaciones entre los humanos, pero igualmente entre estos y los otros componentes no humanos con los que interactúa de forma cotidiana.

Lo sobrenatural, lo natural y lo humano se funden en las identificaciones comunitarias vinculadas a territorios concretos. Por tanto, en "lo comunitario", tenemos una base organizativa, otra identitaria y emocional, y por último una base relacional. Desde este planteamiento lo comunitario pasa de ser un sustantivo a ser un verbo, es decir, un acto, algo que existe en tanto se realiza o hace: en cuanto ente. La comunidad no es algo preexistente a sus manifestaciones, se construye y reproduce desde la acción. Y es en ese hacer en el que los mitos y rituales juegan un papel clave; los mitos en cuanto discursos y los rituales en cuanto prácticas no son una mera manifestación o representación de la comunidad: hacen la comunidad (Azogue, 2016), al actualizar las relaciones entre los componentes humanos y no humanos que la conforman, como una totalidad (Albó, 2011). El ritual implica activar memorias que se ponen en movimiento de forma colectiva, desde la propia acción de los cuerpos (Borea, 2008). Es la acción ritualizada la que permite generar y mantener relaciones, y transformar el espacio informe en un territorio dotado de sentido (Valcuende, 1998), mantener vínculos que se articulan en tramas narrativas, que pugnan con otras prácticas y representaciones, a través de las que se evidencia el conflicto entre el saber científico-técnico y los saberes locales (Santamarina, 2005; Valcuende, Quintero y Cortés, 2011; Valcuende, 2012; Cortés, 2014; Valcuende y Ballesteros, 2019).

En estos procesos de interacción comunitarios la reciprocidad se convierte en un elemento clave para comprender el entramado de relaciones, pero también la significación de los recursos. Sin reciprocidad no pueden funcionar las relaciones sociales. La reciprocidad en el mundo andino rige el intercambio de tierras/servicios y tareas (asumir cargos políticos, religiosos y sociales) desde los escalones más bajos hasta los más altos (Llanque, 2003). En el proceso productivo coexisten diversas prácticas de cooperación simple e intercambio en el trabajo (ayni y $m i n k a^{5}$ ), en faenas comunales, así como en el trabajo al partir, ${ }^{6}$ asalariado y otros (Alberti y Mayer, 1974; Pinedo, 2006).

Pero si las relaciones sociales comunitarias no pueden funcionar sin este principio, tampoco pueden prosperar las relaciones de los seres humanos con los seres no humanos, sean plantas, animales, lagunas, cerros, espíritus o divinidades, que integran un todo que es inseparable. Los humanos tienen toda una serie de obligaciones con los otros humanos, pero también con los componentes no humanos que conforman su socioecosistema, puesto que aquellos componentes están obligados a responder bajo los mismos principios, como posteriormente veremos en algunos de los mitos reseñados. Ambos se articulan desde una lógica que Azogue (2016) considera fundamental en el mundo andino: "dar-recibir-devolver". Como señala Van den Berg (1989, p. 118) para el caso de los aymaras en Bolivia: "La interrelación de todos los componentes del universo y la reciprocidad entre estos componentes revelan un equilibrio fundamental que es la base y el sostén esencial de la existencia misma del cosmos".

5 Ayni, según Alberti y Mayer (1974) es un intercambio recíproco en el cual se presta un servicio a cambio de otro igual en oportunidad futura. Minka también es un intercambio de servicios, en que este se devuelve en la misma forma en que se recibió (pp. 45-46). Importa en el intercambio lo paritario, dentro de lo comunal.

6 Es una denominación que usan los campesinos cuando llegan a acuerdos para cultivar en común productos agrícolas: uno de ellos pone la tierra y/o semillas y el otro, el trabajo; al final se reparten lo cosechado en partes acordadas previamente. 
Las ceremonias rituales son los mecanismos sociales a partir de los que se posibilita mantener un equilibrio que es siempre inestable, provisorio y complejo, en el que participan entidades humanas y no humanas. Desde esta perspectiva, algunos bienes comunes no pueden ser objetivables como se hace desde el discurso tecnocientífico: no son cosas y, más aún, no pueden ser propiedad de nadie, como sucede con los cerros, glaciares, ríos, lagunas, lluvias... Son parte de su kawsay, ${ }^{7}$ ámbito donde se crea y se recrea la vida, en comunión con los seres no humanos. Todos estos elementos se articulan de forma analógica como una unidad fragmentaria (Carrión, 2005). Las transformaciones políticas en la comunidad afectan la significación del medio y de los recursos, pero también los cambios ambientales implican de forma necesaria una transformación en la propia concepción de una comunidad en la que se integran los componentes del medio, incluida el agua en todas sus formas.

Los rituales y mitos articulan todos estos componentes en un proceso de apropiación que trasciende el ámbito de lo local al incluir a los comuneros que hoy viven en Lima, Canta y otras ciudades, y que por unos días vuelven a ser parte de una realidad que es, a un tiempo, próxima y lejana. No podemos olvidar, como señala Cánepa (2001), que "la identidad global solo existe en tanto realidad local, porque los sujetos se constituyen y se experimentan como tales a través de la práctica, es decir, a través de su estar y su hacer" (p. 21).

\section{Caracterización del espacio local}

La comunidad de Cullhuay fue fundada por los españoles con el nombre San Felipe de Cullhuay en $1731 .^{8}$ Esta comunidad campesina es una de las 22 en las que está organizada la población de la provincia de Canta. Ubicada en la sierra del departamento de Lima, forma parte del distrito de Huaros (Figura 1). Fue reconocida como comunidad indígena por el gobierno peruano en 1936.

Un aspecto clave de esta población es su proximidad a la cordillera de La Viuda y al nevado del mismo nombre, en la cabecera del río Chillón, en una altitud entre 3762 y 4800 msnm. El nevado experimenta un proceso acelerado de desglaciación. Para la Autoridad Nacional del Agua (2014), desde 1970 a 2010 se ha producido un retroceso glaciar del 38\% a nivel nacional y este es mucho mayor en el Perú Central, puesto que según los datos de Hidrandina (1988) la superficie glaciar de la cordillera de La Viuda era de $28,6 \mathrm{~km}^{2}$. Los estudios realizados en el año 2007 estimaban que solo quedaban entonces $6,03 \mathrm{~km}^{2}$, lo que significó una pérdida de la superficie del glaciar de $22,57 \mathrm{~km}^{2}$, o sea, el $78,92 \%$ en 37 ańos. Ya hoy quedan apenas unos pequeńos casquetes en la cima del nevado de La Viuda.

7 Kawsay. término quechua que quiere decir "vida” y verbaliza "existir"; indica también, muy significativamente, "comida” (bienes de subsistencia), su amplio campo de significación abarca los medios y condiciones de existencia.

8 El origen de la comunidad indígena campesina de Cullhuay se remonta al período prehispánico. Para Rostworowski (1977) el término Kullhuay corresponde a un curacazgo prehispánico, descrito en las crónicas y documentos españoles tempranos como grupo originario. Con los españoles, formaba parte del señorío preínca de los Atavillos (Alto Chancay), siendo limítrofe con el de los Canta, luego asimilada a este repartimiento por pertenecer a la cuenca sureña. 


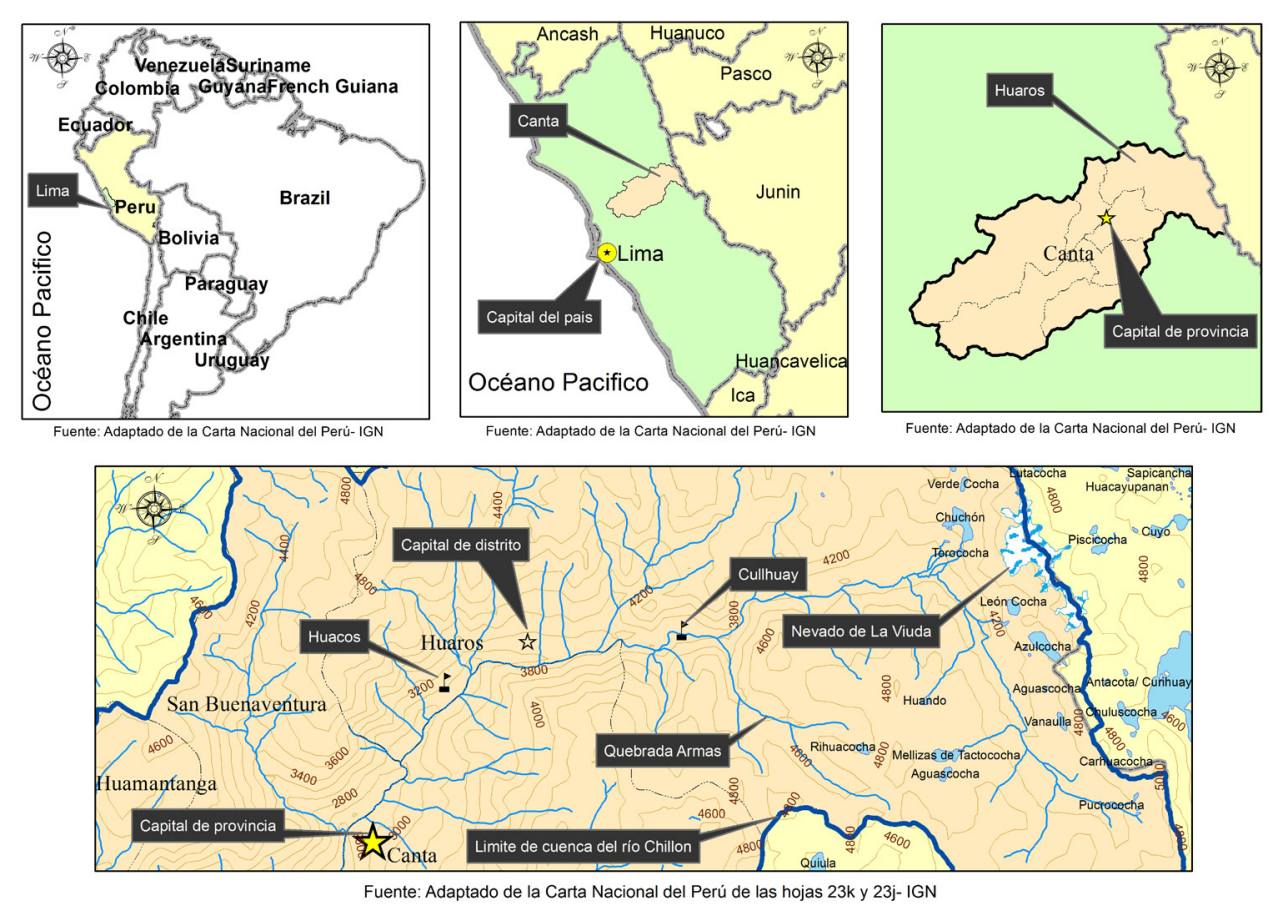

Figura 1. Mapa de ubicación de la Comunidad Campesina de Cullhuay.

Fuente: Adaptado de la Carta Nacional del Perú de las hojas 23k y 23j. IGN (2017).

Según el último censo del Instituto Nacional de Estadística e Información (INEI) de 2017, la población actual es de 286 habitantes; en el censo de 10 años atrás era de 264. De acuerdo al censo llevado a cabo en el 2010 por la posta sanitaria, 86 familias tienen su residencia en el pueblo y 32 familias están distribuidas en las estancias de la puna. El resto de la población reside habitualmente en zonas urbanas fuera de la comunidad.

Esta comunidad es propietaria de una extensión de 10462 ha de tierras, aproximadamente, que se sitúan en diversas zonas ecológicas, los pisos más elevados de la cuenca. De ahí que una de las características del clima sea que es frío y muy variable, dependiendo de la altura de la gradiente. Estas duras condiciones no fueron, sin embargo, un impedimento para que la población humana habitara esta zona desde hace mucho tiempo, desarrollando exitosas formas de adaptación y transformación de ambientes particularmente rigurosos y frágiles, conformando una variedad de zonas de producción y sistemas de tenencia de la tierra.

Actualmente, la principal actividad productiva es la crianza extensiva de ganado, sobre todo de ovinos, vacunos y caprinos. Las transformaciones experimentadas en el medio y los intereses del mercado han potenciado la ganadería en perjuicio de otros cultivos que ahora tienen un carácter económico complementario, como sucede con los cultivos de tubérculos en las laderas de los cerros, donde se construyeron andenes, llamados warkes (Figura 2). Son cultivos destinados al autoconsumo, por lo que habitualmente se recurre a la fuerza de trabajo de la familia extensa o a los vecinos, a quienes se convoca para realizar las faenas a partir de relaciones de reciprocidad. 


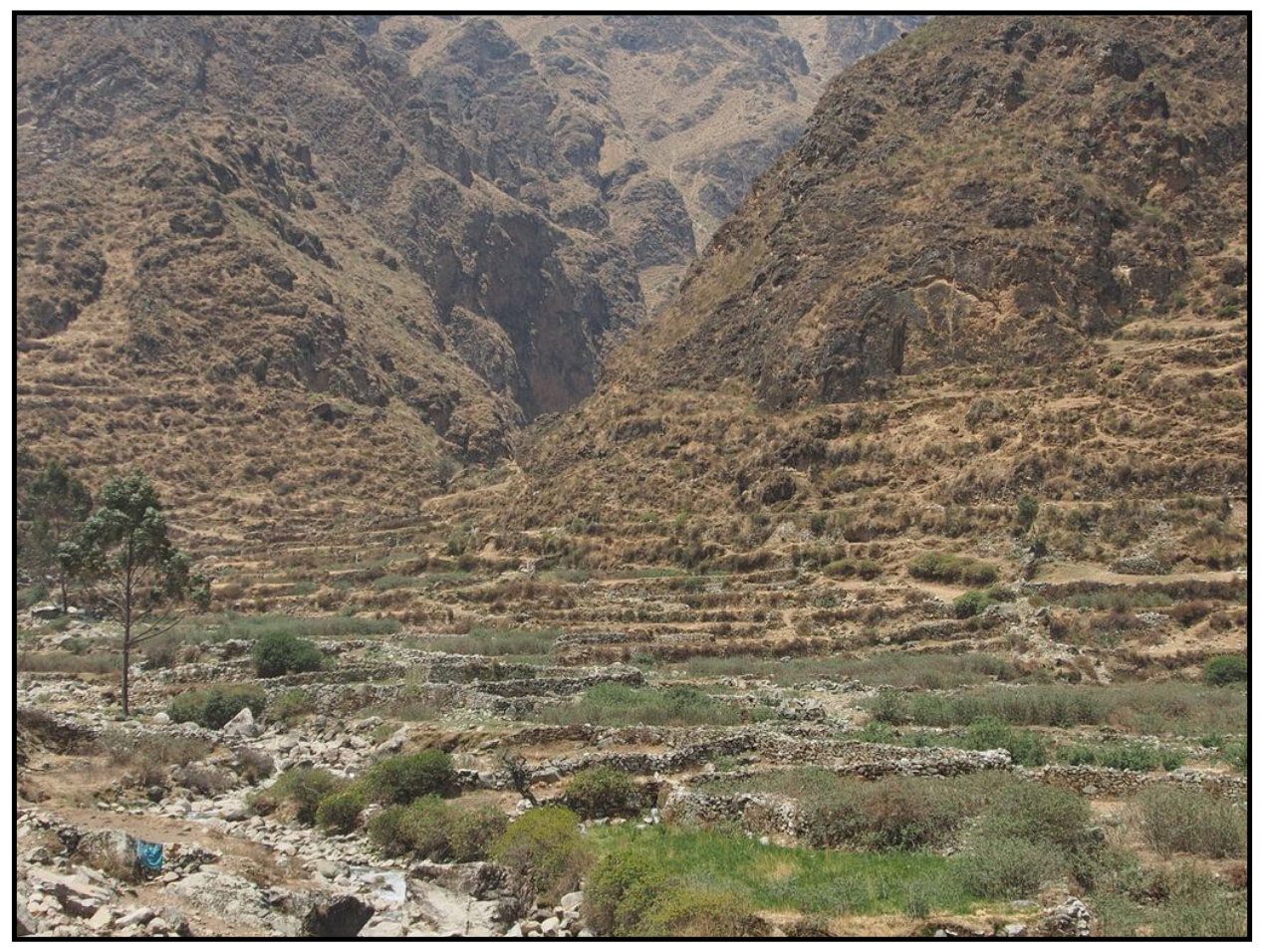

Figura 2. Los warkes. Fuente: Fotografía Víctor Mallqui (2016).

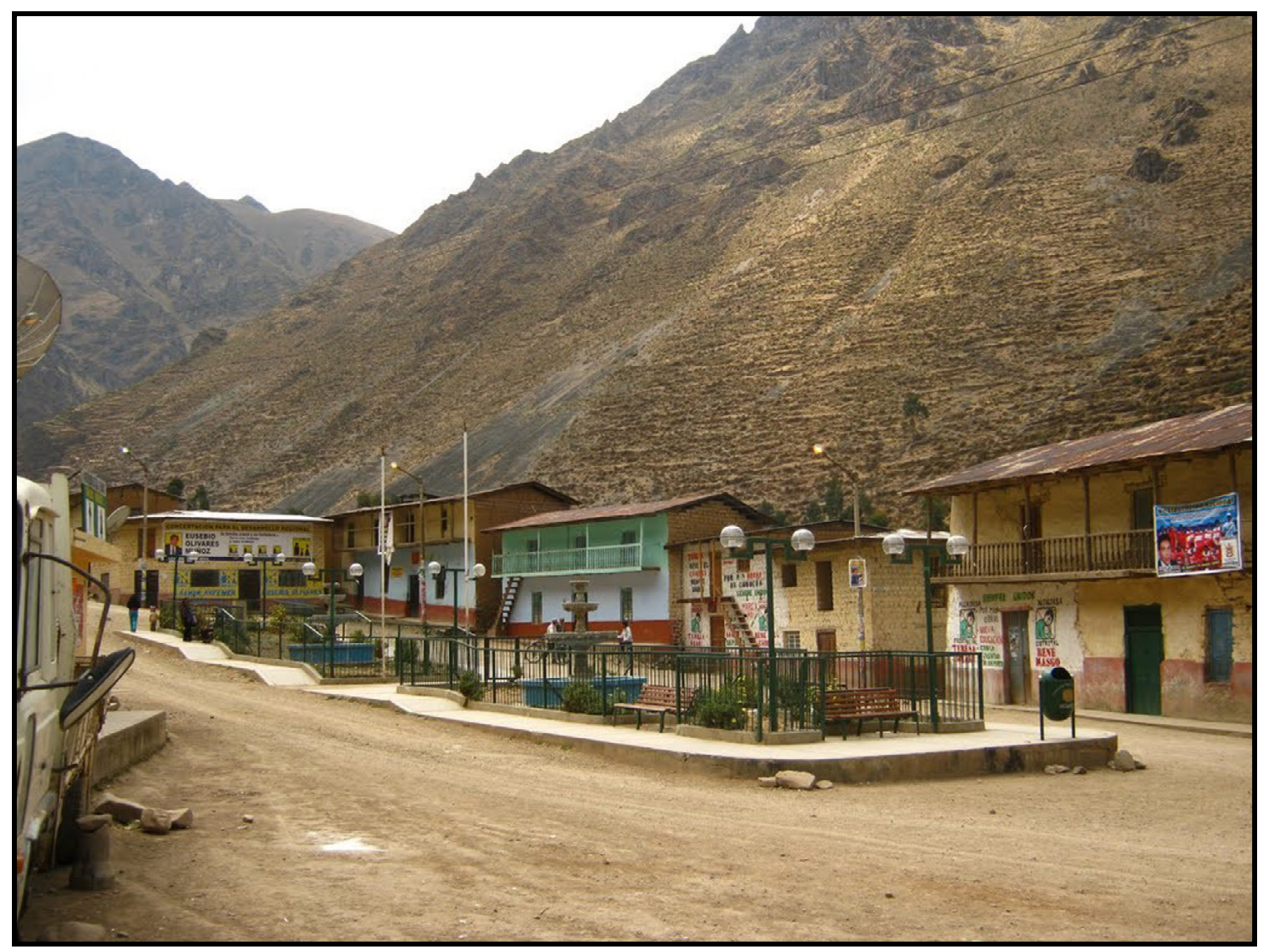

Figura 3. El pueblo de Cullhuay. Fuente: Blog spot Cullhuay (2011). 
Estas actividades económicas han permitido la vida humana, gracias principalmente a la construcción de complejas prácticas de gestión comunal y familiar de los recursos biofísicos (Golte y De la Cadena, 1983; Mossbrucker, 1990). Los saberes locales sobre el entorno posibilitaron estrategias de manejo y de adecuación a las condiciones de un clima a veces impredecible, que juega un papel fundamental en las actividades humanas y en el imaginario colectivo (Rösing, 1996; Goloubinoff, Katz y Lammel, 1997; García, 2012).

Ahora bien, los saberes y las formas de gestión local se ven influidos por una serie de cambios políticos que de forma progresiva afianzan las estructuras estatales en los contextos locales, lo que se traduce en una transformación de la representación política, tal y como señala Damonte (2016).

Desde el final del período republicano las comunidades en general, y la comunidad de Cullhuay en particular, han experimentado una progresiva inserción en las estructuras estatales, tendiente a reducir su capacidad de autogestión, en un proceso que se vio agudizado en la época fujimorista y en el período de Alan García (Varas, 2017). A nivel local y más allá de las transformaciones globales que afectan a las comunidades en Perú, hay algunos hechos importantes a nivel local, que van a afectar notablemente la reestructuración de las relaciones económicas y políticas de la propia comunidad y que merecen ser mencionados, aunque sea en forma breve.

Uno de los cambios más significativos ha sido la mejora de comunicaciones y la construcción de la carretera en la que participaron los vecinos, que se inició en 1932 para finalizar 25 años después. De esta manera se conectó la comunidad de Cullhuay (Figura 3) con la capital del país, con ciudades y pueblos de Junín y con las minas de Cerro de Pasco. Este medio de comunicación fue muy significativo para los cullhuaínos, pues contribuyó a facilitar su traslado a centros mineros para trabajar; además, permitió acortar el tiempo de traslado y comercialización de la producción ganadera hacia Canta, Lima y centros mineros, así como acceder a centros educativos para recibir educación secundaria y también superior.

La comunidad, de forma progresiva, se va conectando al mundo urbano, y esto no solo queda de manifiesto en la construcción de infraestructuras, también en los procesos de migración, que implicarán que una parte de los comuneros se marchen a los centros urbanos, como a Cerro de Pasco, Huancayo, Canta y especialmente a la capital, Lima (lo que se ha traducido en una significativa pérdida de población). Todos estos hechos repercutieron en cambios muy importantes, como la cada vez mayor presencia de instituciones estatales, escolarización con progresivo proceso de "castellanización", o bien en cambios en las tomas de decisiones, que ahora deben compatibilizar los intereses de los comuneros residentes con el de los comuneros emigrantes. Estas transformaciones, como no podía ser de otra manera, se han evidenciado también en las formas de gestión del agua.

Una buena parte de las acciones del Estado han ido encaminadas a posibilitar el uso del agua en otras zonas, dado su carácter estratégico. La acción directa del Estado sobre los recursos hídricos de Cullhuay se materializa desde los años treinta del siglo pasado, cuando se construye la represa en una de las lagunas: la de Chuchún, y se crea el acueducto a cielo abierto que trasladará el agua a lo largo del tramo vial (Ecoplaneación Civil, S.A. (ESCA), 2012). Es en ese período cuando el Estado comienza a intervenir en la parte alta de la cuenca, para extraer agua proveniente de los glaciares y las lagunas de la cordillera de La Viuda (Figura 4), con el fin de responder a la presión por el agua de los habitantes urbanos limeños, de las empresas industriales, energéticas y de los agricultores de las cuencas medias y bajas. Pero la conversión de un recurso local en un recurso global implicará de forma progresiva la implementación de 
un nuevo marco legislativo. En este sentido será fundamental la Ley de Aguas de 1969, que dejará en el limbo la situación de las cabeceras de las cuencas, desarrollándose otras actividades que no van a tener en cuenta los derechos consuetudinarios de los comuneros (Varas, 2017, p. 20). Con esta normativa el Estado asumió el control del recurso hídrico y estableció su propiedad exclusiva sobre las aguas, tanto superficiales como subterráneas. Fue al amparo de esta legislación que las empresas privadas y organismos gubernamentales realizaron estudios sobre la potencialidad de los recursos hídricos en esta región, con el objeto de abastecer a las zonas agrícolas, industriales y urbanas costeñas.

El sistema hidráulico construido por el Estado se sustentó en una nueva institucionalidad y en la burocracia estatal creada para su desarrollo. De esta forma, aparecen nuevos actores que gestionan los recursos hídricos, como la Junta de Usuarios, que agrupa a 15 comisiones de regantes de la región Callao y Yangas (Canzino y Valcárcel, 2000). Los personeros responsables de la administración de la Autoridad Local de Aguas (ATDR) reconocen que en la parte alta de la cuenca las organizaciones de regantes no son reconocidas ni están legalizadas. "Se les está informando a la población que las tierras son suyas, pero que el agua es del Estado" (Entrevista técnico de ATDR, Huaral, febrero de 2012).

De esta manera se ha ido debilitando el poder de los cullhuaínos en el manejo del agua, al despojarla de sus ámbitos sagrados, originando un conflicto soterrado entre los modelos de manejo y uso de esta. Entre tanto, los comuneros continúan utilizando las acequias antiguas del pequeño sistema de riego de Huaipa, ya que los funcionarios no la integraron al moderno sistema de riego.

El manejo de las lagunas ha pasado a ser gestionado por el Estado. Sin embargo, en Cullhuay la resistencia a la normativa estatal en el manejo del agua se manifiesta en la persistencia de las formas locales tradicionales de riego, en el rechazo a pagar la tarifa de agua, en la inasistencia a

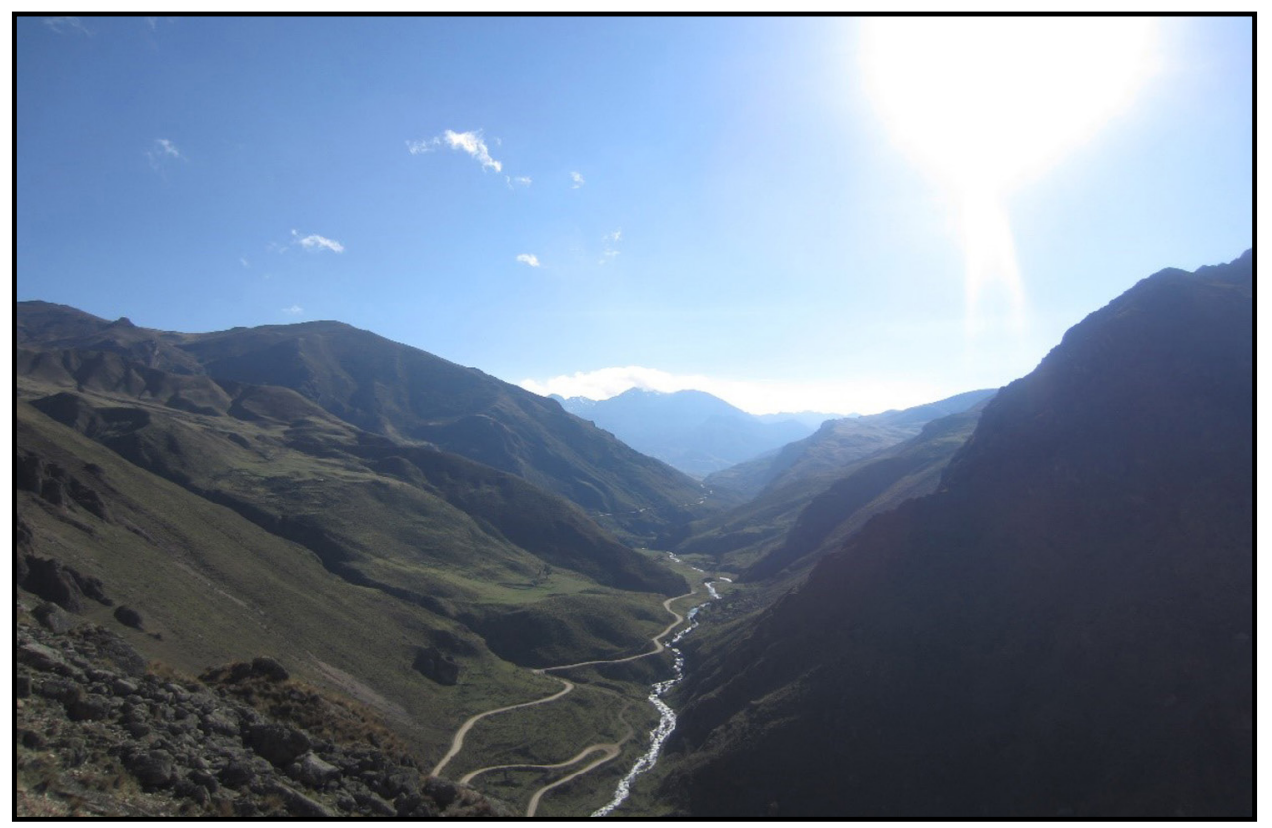

Figura 4. Nevado de La Viuda. Fuente: Autores. 
las reuniones convocadas por los funcionarios de diferente rango de la ANA o el gobierno regional. Unos mecanismos de resistencia que se hacen evidentes en narrativas y rituales a partir de los cuales los comuneros se vinculan con este recurso.

\section{Mitos y rituales}

La cosmovisión de los cullhuaínos - como sucede a nivel general con las sociedades andinas- ha estado relacionada estrechamente con el agua en sus diferentes manifestaciones (glaciar, lagunas, agua de lluvia, agua "domesticada" de los canales de riego). Si bien en esta zona la lluvia es abundante en la estación húmeda, sin embargo, las precipitaciones están marcadas por la incertidumbre e inestabilidad, por lo que, ante las potenciales crisis (como la sequía), los habitantes de Culhuay han llevado a cabo acciones simbólicas que les permiten intervenir sobre el mundo socio-bio-espiritual con el que se relacionan.

Las conexiones culturales con el agua y los paisajes de la población comunera son muy vivas y complejas. Para ellos el agua es algo más que un recurso esencial; en él se reflejan sus concepciones sobre el entorno y la relación entre todos sus componentes (Goloubinoff, Katz y Lammel, 1997; Heyd, 2011; Ulloa, 2011). Los vínculos entre los humanos, y entre estos y el medio, se establecían a través de seres intermediarios que son invocados en las ceremonias y rituales, durante todo el calendario anual, en el que se realizan ceremonias religiosas en las cuales solicitan a estos seres "espirituales" que las fuentes de agua, sobre todo la lluvia, continúen.

Se trata de un mundo religioso donde se fusionan de forma sincrética creencias prehispánicas y católicas. Hay una continuidad cultural de los ritos de la lluvia desde la época prehispánica hasta nuestros días, a pesar de haber transcurrido más de 500 años desde que la presencia española intentó interrumpirlos (Arriaga, cit. por Borea, 2004). Una presencia activamente innovadora que se ha traducido en la introducción de nuevos elementos culturales que contribuyeron a redefinir las costumbres, rituales y devociones, de la misma forma que también se adoptaron nuevos cultivos y animales.

La cosmovisión prehispánica está presente en la vida de los comuneros, no solo en sus cerros protectores o intermediarios, los apus (a los que dedican ceremonias y rituales la primera semana de mayo, en la Fiesta de las Cruces), sino también y sobre todo en las fuentes de agua.

Los apus observan la vida de la comunidad bajo su protección, protegen la salud de la gente y de los animales, controlan el clima. Los apus tienen su propia jerarquía; los regionales tienen más rango y poder. Tanto los locales como los regionales velan por la armonía de la comunidad, el bienestar de los rebaños, pero los intereses de los locales se limitan exclusivamente a su propio grupo local. Los apus regionales tienen un valor absoluto (Brachetti, 2005, p. 56).

A las lagunas, donde acuden los comuneros en determinadas épocas del año a realizar rituales, se las considera pacarinas. ${ }^{10}$ Cada cerro, cada laguna es personificado; conforman lo que Heyd (2010) definiera como una heterotopía. ${ }^{11}$ Una de las lagunas más significativas para esta

9 Fuerzas naturales, dioses.

10 Lugares de origen, sagrados.

11 Un lugar seńalado y propio, con mucha subjetividad, un sitio distintivo; que para los pobladores de ese espacio no es intercambiable. 
población ha sido la de Chuchún (Figura 5). En ella, que fue un lugar de peregrinaje, se realizaban rituales para agradecer y pedir la llegada de las lluvias. Chuchún era el punto de encuentro entre los humanos y los no humanos, de las aguas superficiales y subterráneas del glaciar, de la cuenca alta y la baja (Sherbondy, 1995). ${ }^{12}$

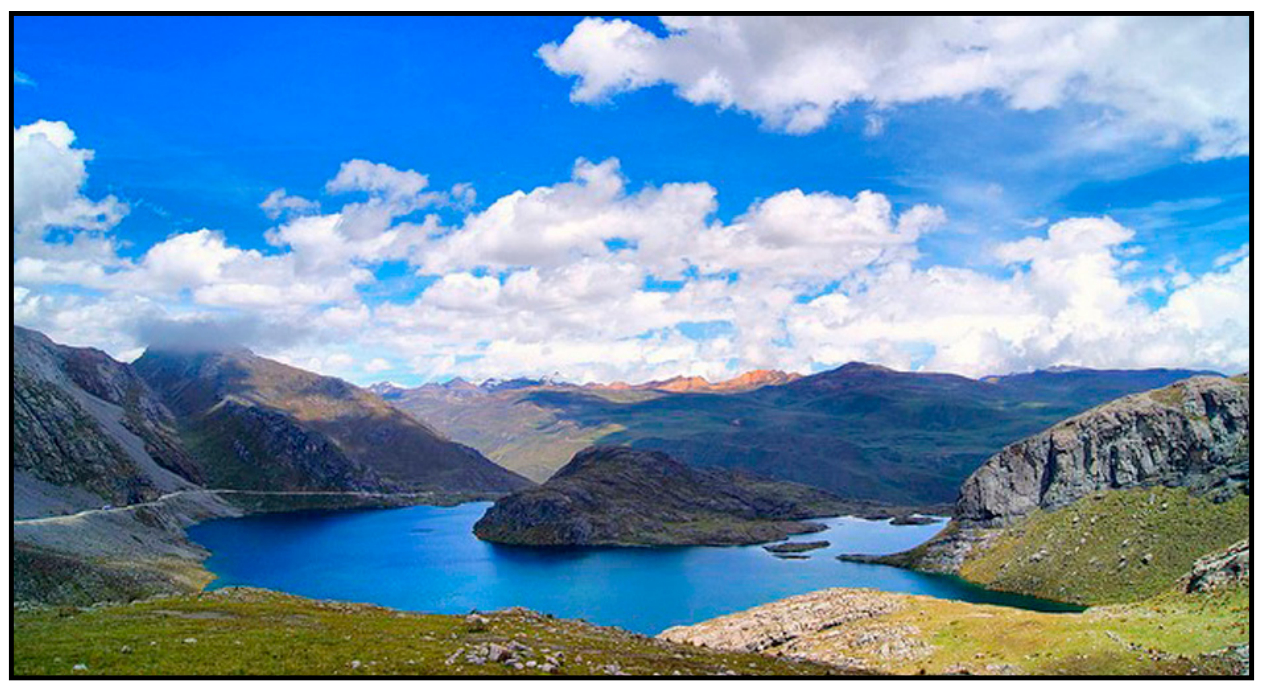

Figura 5. Laguna de Chuchún. Fuente: Fotografía de Víctor Mallqui (2016).

La laguna cobija en su seno un ídolo de piedra (huaca) de color negro: ${ }^{13}$ la Viuda del Dios Pachacámac. Para los comuneros tanto la Viuda, como el nevado de su mismo nombre, que está situado en la parte alta de la laguna, son suyos. ${ }^{14} \mathrm{El}$ ídolo de La Viuda podía ser contemplado por los lugareños en los meses más secos del año: julio y agosto, período en el que bajaba el nivel de las aguas de la laguna. Cuando las lluvias se retrasaban, la comunidad iba en procesión hasta las orillas de la laguna a realizar ofrendas y rituales para que lloviera y propiciar así el renacimiento de los pastos, el brote de los cultivos y la reaparición de los manantiales... En uno de nuestros viajes a la laguna uno de los comuneros nos comentaba:

\section{En un costado de la laguna habia una roca que, a una distancia de $100 \mathrm{~m}$, daba la apariencia de una mujer vieja, a la que se llamaba La Viuda. Alli se hacian los pagos para tener mejores crianzas y buenos cultivos. En algunas ocasiones, los comuneros lanzaban piedras con hondas a La Viuda, pidiéndole que haga llover. ${ }^{15}$ Ahora la roca desapareció, porque se inclinó y además con la represa aumentó el nivel del agua y la cubrió (señor Pastrana, Cullhuay, 9 de octubre 2014). ${ }^{16}$}

12 Esta antropóloga define el papel articulador que tenían las lagunas como vías de comunicación entre diversos planos en el mundo andino.

13 Las huacas son testimonios de las culturas precolombinas que se desarrollaron en este espacio y que tuvieron su propia integridad religiosa. Está lejos de la intención de este trabajo buscar los significados originales de las mismas; sin embargo, su presencia en la vida cotidiana de los cullhuaínos contemporáneos interesa como un símbolo de los significados y valoraciones que estos tienen de su entorno.

14 El nombre original en quechua está perdido, los actuales comuneros no lo recuerdan.

15 Con estas hondas arrojaban a la "huaca" depósitos de cerámica llenos de sangre de camélidos, para que al llegar se rompieran y la cubrieran.

16 En los años treinta el Estado peruano comienza a preocuparse por el agua de esta zona creando una 
Las narraciones de los mayores cullhuaínos, que mantienen en su recuerdo un conjunto de mitos y leyendas, expresan un continuum entre elementos humanos y no humanos. Lo comunitario se extiende a los componentes no humanos, con los que es necesario mantener una serie de relaciones. Conviene que nos detengamos en uno de los mitos todavía vivos entre los comuneros, el de Wa Kon y la Viuda.

\section{Leyenda de la Viuda y el dios Wa Kon}

Uno de nuestros informantes, Santiago, cuenta que Cullhuay era una zona donde se habían generado muchos mitos que le contaron sus padres, ya fallecidos. Sobre la laguna de Chuchún y el glaciar de La Viuda, nos narró la siguiente leyenda:

El dios Huiracocha tenía varios hijos, uno de ellos, el mal hijo, se llamaba Wa Kon, ${ }^{17}$ al que su hermano Pachacámac lo había botado de la zona de la costa a la sierra. Este era malo porque se comía a los niños. Por eso en Cullhuay cuando los padres quieren hacer asustar a sus hijos para obligarlos a que coman les dicen "ya viene el Wa Kon". En esos tiempos antiguos, llegó hasta Cullhuay una mujer, que era la viuda del dios Pachacámac, con sus dos hijos, y alli en unas cuevas se encontró con Wa Kon, que quería algo con la madre, por eso él envió a los dos niños a traer agua en canastas de unos puquios lejanos. ${ }^{18}$ Cada vez que los niños cargaban el agua, esta se escurría, por lo que tardaron bastante. Una añás (zorrillo hembra), que los vio en esta inútil tarea, les dijo que volvieran rápidamente al lugar donde estaba su madre con Wa Kon, pero al llegar al lugar no encontraron ni a Wa Kon ni a su madre. La zorrilla les dijo que debian esconderse. Pero en el sitio habia una olla hirviendo tapada. Cuando abrieron la olla, vieron a su madre. De sus pechos salia un ruido: "Whish, whish". Habia sido muerta $y$ descuartizada por Wa Kon. Se fueron corriendo y se escondieron. Cuando llegó Wa Kon no encontró a los niños, y salió en su busca. En el camino se encontró con varios animales, entre ellos con la zorrillo y le preguntó por los niños. Le respondió que ella sabia dónde estaban y le indicó un lugar cerca de un precipicio. Cuando Wa Kon se puso a atisbar, la zorrillo le decía: "Acércate más, y más, ellos están en esa cueva". Cuando estuvo muy cerca, la añás le dio una patada que lo tiró precipicio abajo, matándolo.

Antes de terminar el relato el comunero señaló con su dedo la cueva que estaba al frente de donde conversábamos, en una de las laderas del pueblo, a un costado del actual bosquecillo de pinos y a la que ellos denominan Herraje. ${ }^{19}$ "Allí está -dijo- Wa kon". Y prosigue su relato:

Los restos de La Viuda son llevados hasta la laguna Chuchún, donde la depositan, se convierte en una piedra negra (ver Rostworowski, 1978). ${ }^{20}$ Aun hasta ahora está y

represa que afectará a esta laguna y que será inaugurada en 1938. Entre 2010 y 2015 se ha ampliado a $9000000 \mathrm{~m} 3$ por parte del gobierno regional Lima-provincias (entrevista a funcionario regional).

17 El recuerdo del dios Con, olvidado por los yungas, se conservó en las serranías con la figura de un genio maligno, siguiendo un movimiento migratorio de la costa a la sierra (Rostworowski, 1978, p. 186).

18 Puquio, en quechua pukyu, significa 'manantial'.

19 Hoy esa cueva que la llaman del Herraje se encuentra en la ladera de ese cerro, es un área entregada en concesión a la empresa Cementos Lima, para la explotación de óxido de cal y arcilla.

20 "El hecho que el ídolo fuese una piedra redonda, no una figura humana, como lo afirma Garcilaso, está más de acuerdo con las costumbres indígenas y con las múltiples relaciones que ofrecen los extirpadores de idolatrías" (Rostworowski, 1978, p. 70). 
se la observa cuando baja el agua. Y por eso se llama al nevado que desagua en esta laguna como el Nevado de La Viuda.

El mito de La Viuda y del dios Wa Kon es una forma de interpretar/crear paisaje, en función de los hitos que consideran centrales en su territorio (la laguna, el nevado, las cuevas, los canales de riego, los andenes, los caminos). Permite aprehender la relación entre animales, humanos, espíritus y seres inanimados que integran la comunidad. Los elementos centrales del mito refieren al agua, las lluvias, las lagunas, el hielo (Carrión, 2005). El mito ordena el territorio y lo hace desde un discurso moral, proporcionando los elementos necesarios, que serán activados en diversos rituales, para asegurar algo que es fundamental para la subsistencia de la comunidad: el control espiritual del agua; un elemento vital en torno al cual siempre pesa la incertidumbre.

Los rituales en los que se encarnan los mitos deben satisfacer a La Viuda y otras huacas a partir de los intermediarios, los paqos ${ }^{21}$ andinos, capaces de dialogar con ellas (Sherbondy, 1995; Cruikshank, 2005). Hay elementos interesantes en estos relatos que confirman la centralidad de la reciprocidad con estas entidades sobre-bio-naturales. Los comuneros dependian de La Viuda y ella es la que tenía la posibilidad de mandar las lluvias. Ahora bien, si La Viuda no cumplía, era castigada: "se le tiraban piedras". Y es que no podemos olvidar el carácter de la vinculación humanidad-dioses, como ya apuntara Durkheim:

Incluso, en relación a sus dioses, el hombre no está siempre en un estado tan acentuado de inferioridad; pues ocurre con mucha frecuencia que ejerce sobre ellos una verdadera compulsión física para obtener de ellos lo que desea [...]. Se lanzan piedras, para obtener la lluvia, contra el manantial o el lago sagrado donde se supone que reside el dios de la lluvia; por este medio, se piensa obligarle a salir y a mostrarse. Por demás, si bien es verdad que el hombre depende de sus dioses, esta dependencia es recíproca. También los dioses tienen necesidad del hombre; sin las ofrendas y los sacrificios se morirían (Durkheim, 1982, p. 34).

\section{Leyenda de las Tres Hermanas}

En la leyenda de las tres hermanas se da sentido a un paisaje que adquiere un carácter mágico y que se vincula a diversos seres sobrenaturales, que al mismo tiempo forman parte de una naturaleza que no puede ser explicada desde estas lógicas como una realidad puramente racional ni material.

Hace mucho tiempo, llegaron a esta zona tres mujeres que eran hermanas: La Viuda, Puma Quihuay con su marido, y Riguacocha, que estaba sola. Ellas vinieron a fundar las lagunas. Las hermanas dividieron el espacio y se distribuyeron a qué lugar ir. La Viuda llegó a la laguna Chuchún y alli se quedó convirtiéndose en la piedra negra. Riguacocha se fue a otra laguna y la otra, que quería separarse del marido, se quedó en el puente Jotachaca, pero su marido le tiró un hondazo, le quitó un pecho, matándola, y se convirtió en piedra, quedándose en la zona de Puma Quihuay, desde donde contempla todo el paisaje. Cerca de alli los antepasados construyeron su centro poblado y fortaleza (Rafael Navarro Soto, electricista y pintor, com. pers., Cullhuay, 8 septiembre 2014).

21 Sacerdotes andinos. 


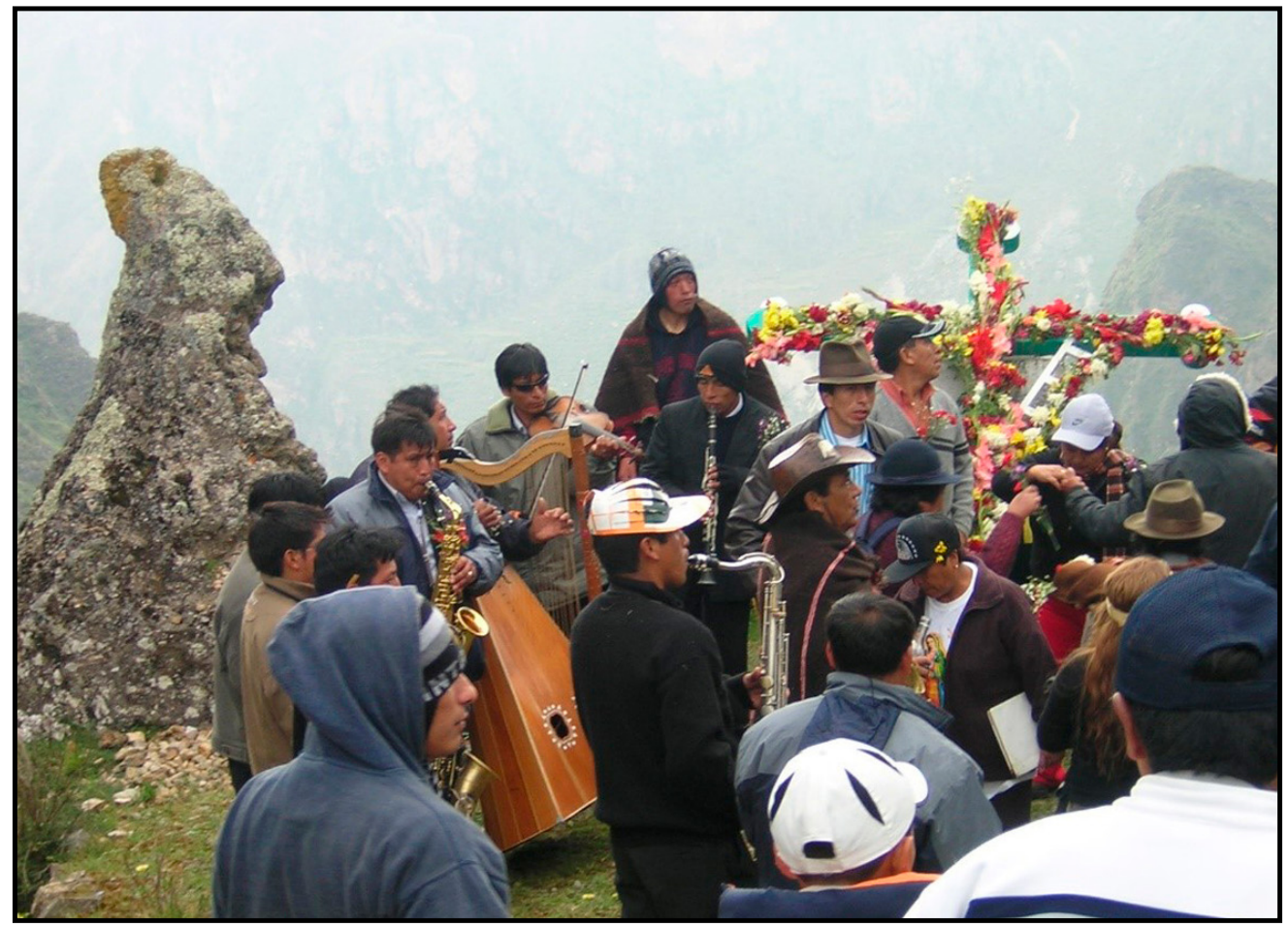

Figura 6. La huaca de Puma Quihuay. Fuente: Fotografía de Blog spot-Cullhuay (2011).

En un segundo relato de esta misma leyenda se señala que los ídolos de piedra fueron tres hermanas, hijas de Pachacámac: Puma Quihuay, Riwacocha y Chuchuncocha. Las tres hermanas ingresaron por la quebrada de Chichicara del cerro Waqonpahuashen y se dirigieron por la quebrada de Arma. La segunda hermana es la laguna en la que al fondo se encuentra el ídolo, la tercera está en la laguna de Chuchuncocha, en el nevado de La Viuda.

La primera, la huaca de Puma Quihuay (Figura 6) es un ídolo de piedra famoso no solo por su tamaño, sino por las extrañas y caprichosas formas, perfil y figuras que se advierten en su superficie. El ídolo se encuentra en las faldas de Gasgachin o Parimachay de la quebrada de Arma, junto al adoratorio Puma Quihuay. A lo lejos se ve a una mujer que lleva un "quipe" en las espaldas. Según la leyenda esta mujer o vieja lleva cargando a sus hijos, los willcas. En honor a estas tres hermanas se celebra la danza de los parianes, que tiene lugar durante la limpia de la acequia, el 15 de junio de cada año. ${ }^{22}$

Y es que el mito en cuanto explicación e interpretación de la realidad no solo es discurso, es también acción a partir de los rituales. Conviene que nos detengamos para profundizar en estos aspectos, en la fiesta del agua, en la que se retoman todos estos componentes que articulan en el discurso y en la propia acción a todos los elementos que conforman el socioecosistema.

22 Versión del docente universitario de San Marcos, cullhuaíno, Luis Cajavilca Navarro, en Lima, noviembre de 2015, que sensiblemente falleció en 2017. 


\section{La Fiesta del Agua o Champería}

La fiesta del agua es conocida también como "Limpia acequia" o Champería, ${ }^{23}$ pues es el momento en el que el colectivo comunal realiza el mantenimiento del sistema prehispánico de riego, aún en uso, constituido por tomas y acequias (Tello y Miranda, 1923; Gelles, 1984; Ráez, 2002). ${ }^{24}$

Los mitos y leyendas de origen, como La Viuda, el dios Wa Kon y las Tres Hermanas (relacionados estrechamente con el agua de las lagunas, el agua de lluvia y el agua domesticada en el sistema de riego), son el sustento discursivo de los diferentes rituales que se desarrollan en estos días. Uno de los personajes que juega un papel central en esta fiesta es la huaca llamada Puma Quihuay.

No haremos un relato exhaustivo de la Fiesta del Agua en Cullhuay, al respecto se puede revisar el artículo de Borea (2004), quien realiza una minuciosa narración y análisis. En esta oportunidad nos interesa resaltar el manejo del recurso hídrico relacionado con los fenómenos meteorológicos en la cabecera de la cuenca y la vigencia de este imaginario, sus representaciones y significados entre los comuneros (Farfán, 2002).

Las celebraciones que se desarrollan durante los días 14 y 15 de junio coinciden con el final de la cosecha de tubérculos. Se inicia reconociendo el tejido social tradicional, la autoridad del apoderado. En la asamblea realizada en días previos, en la que se involucran todos los comuneros, se elige a las autoridades rituales (que cumplirán roles específicos solo para esta ocasión suplantando a las autoridades formales), y a los encargados de desempeñar roles de personajes rituales en la ceremonia del segundo día.

\section{El 14 de junio se realiza la limpia de la acequia, la organización depende de las auto- ridades. Y llevan un huaco de los antepasados. Van hasta la toma de agua que queda en la altura. Alli los hombres limpian la acequia y las mujeres los esperan abajo con la comida. Llevan su pajita, los hombres les quitan, y las mujeres les dicen a ellos "las zorras". Los hombres sacan agua del río Pasora, de abi entra el agua para el regadio. También tienen las familias terrenas con riego (mahuay). Son canales de tierras que a veces se rompen y el agua se anega. Aunque hay ahora algunos tramos que están con cemento (Eloísa Bandán, com. pers., Cullhuay, agosto 2014).}

El 15 de junio los comuneros, conjuntamente con sus autoridades tradicionales (el apoderado) se desplazan hasta las zonas místicas como es el mencionado río Pasora en la quebrada de Armas, cerca de la cueva de Pariamachay y a un costado de la bocatoma.

Hay costumbre, el 15 de junio después de limpiar las acequias, de juntarse en la quebrada de Arma. La gente lleva harta comida, todos sus platos. Llevan banderas. Tocan tinya [un tamborcito] las viudas. Asisten las autoridades, y alli acuerdan

23 Champería (quechuización derivada de champas: pedazos de césped cortado con lampa (voz quechua) que se usan para dirigir el riego cubriendo los surcos; al reparar los canales mediante faenas en la comunidad, este instrumento corta así el sedimento que obstruye el flujo adecuado del agua.

24 Esta fiesta se realiza en casi todas las comunidades de la sierra limeña, la más difundida es la de San Pedro de Casta en el valle de Santa Eulalia; en cada una de ellas toma características locales específicas, y se lleva a cabo en distintos momentos del año. 


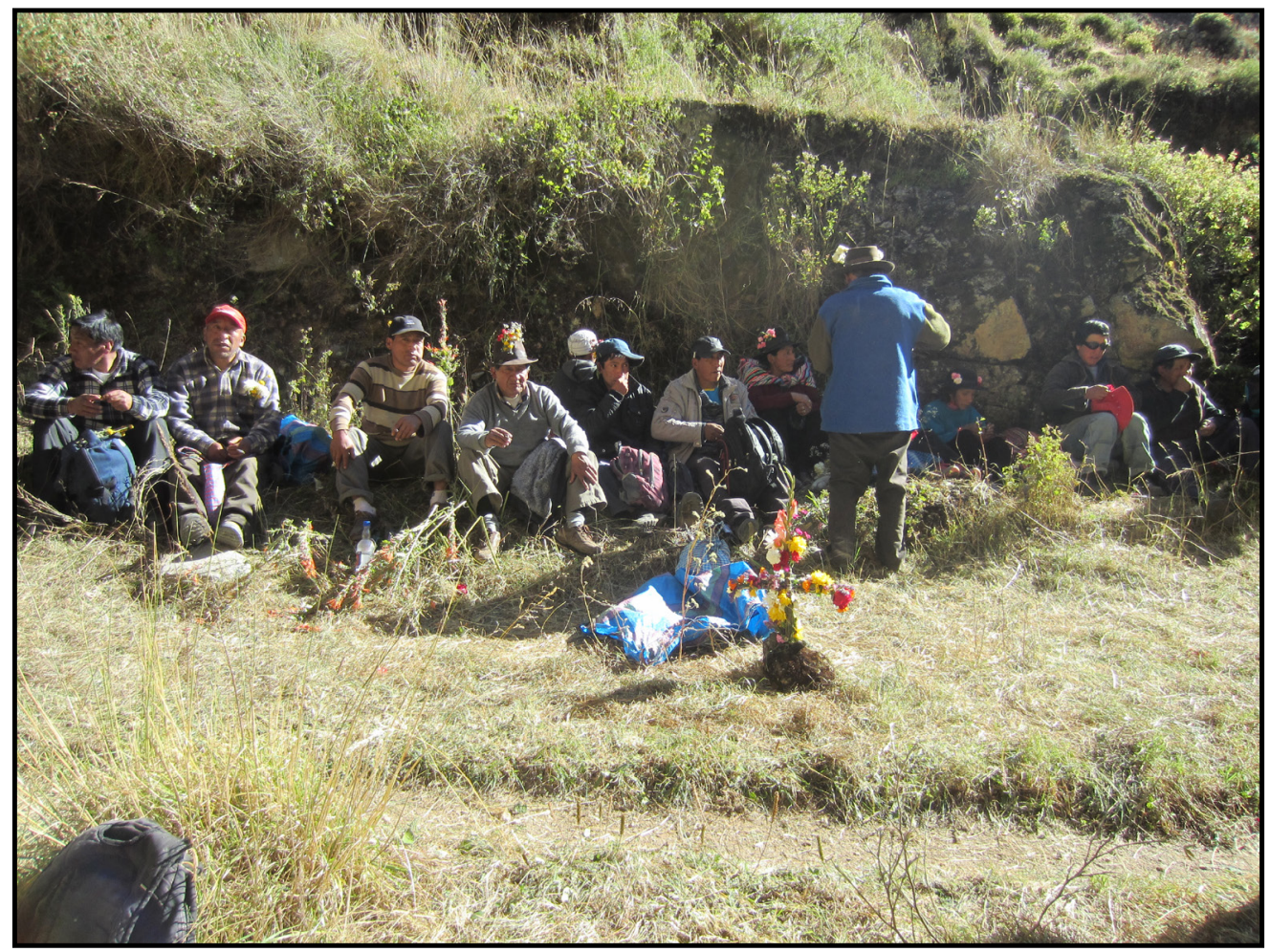

Figura 7. Fiesta del Agua. Fuente: Autores.

nombrar al juez de aguas. Alli se bautizan a los niños, a los jóvenes, asi nacen los compadrazgos. Yo he bautizado a varios, por eso me dicen madrina y padrino a mi esposo. De alli tarde llegan a la casa comunal (Eloísa Bandán, com. pers., Cullhuay, agosto 2014).

Ese día en la fiesta de la Champearía o del Agua (Figura 7), todo se invierte: se cambia en estos días el nombre de las cosas, de la misma forma que se cambian las autoridades, incluso los hombres asumirán cargos de zorras hembras, "travistiéndose" de mujeres. Los humanos asumen el papel de animales silvestres, se habla a los elementos de la naturaleza y se invoca a las huacas para que traigan las lluvias. ${ }^{25}$

En el ritual sagrado los/las Parianas, el grupo de comuneros hombres que se disfrazan de zorras se colocan en una esquina, distantes del conjunto de comuneros que están sentados conversando, fumando, bebiendo alrededor de unas cruces de flores. Los Parianas se empujan entre ellos, hablan en falsete, lanzan bromas, se ríen. Son expresiones de que en esta Fiesta del Agua el mundo se trastoca: humanos convertidos en animales hembras, que según el mito trastocaron el orden al derrotar a Wa Kon.

La persistencia de este ritual permite que se refuerce la organización colectiva tradicional en torno al manejo del agua, así se involucra en el mantenimiento de los canales de riego a todos los comuneros (los que permanecen en los espacios comunales y aquellos que no), los no

25 Información proporcionada por Tomasa Pastrana, Cullhuay, agosto de 2014. 
comuneros y los forasteros que tienen algún vínculo con la comunidad. Todos los habitantes participan conformando una unidad. Los dirigentes y comuneros participantes contribuyen a cubrir los gastos del ritual con diferentes aportes (dinero, coca, cigarros, alcohol, etc.). Es una ocasión para refundar la condición de comunero o comunera participando activamente en las ceremonias, renovando así sus derechos de acceso al agua, a las tierras y a los pastos, tal y como se establece en el derecho consuetudinario andino (Sherbondy, 1995). En esta ocasión se visualiza y se renueva la estrecha relación entre los ecosistemas suni y jalka (Pulgar Vidal, 2014). ${ }^{26} \mathrm{Si}$ bien en esta ceremonia lo central es el agua domesticada, esta se encuentra estrechamente relacionada con las fuentes que están en las alturas: las lagunas, el glaciar, las aguas subterráneas, y sobre todo las lluvias. Si en el ritual se hacen presentes los pastos de la jalka, también aparecen otros elementos del ecosistema, como la fauna: zorros, sapos, aves. La realización de estos rituales y ofrendas permite abrir canales de comunicación entre los humanos y las deidades del agua. Unas deidades a las que conmemoran y agradecen y con las que establecen relaciones de reciprocidad a las que ellas deben responder con la aparición de lluvias abundantes.

La comunidad expresa, a través de este ritual, las estrechas relaciones de reciprocidad con los habitantes no humanos de su entorno. En ese encuentro se revela la identidad colectiva frente al poder de los apus para atraer la lluvia. Se les pide que traigan la lluvia, la fertilidad. El tiempo no termina con la fiesta, sino que continúa hasta la Fiesta de las Cruces, cuando se culmina el ciclo agrícola y ganadero.

Al final, se oficia un banquete ceremonial ${ }^{27}$ (Figura 8), donde se reciproca con el agua en el momento en que se abre la bocatoma para posibilitar el riego. Se entrega así al agua "liberada" su comida ritual: coca, flores, dulces; luego las familias participantes bajan hasta los campos de huaipa e intercambian entre sí comida exageradamente abundante y diversa. De esta manera la fiesta es una manera de agradecer al agua, haciéndola sentir cómo ella es vital para sus vidas y mostrándole cómo ellos son solidarios entre sí. La reciprocidad se convierte (como señaláramos al tratar de la comunidad como realidad socioambiental) en la base del funcionamiento de las sociedades andinas en su medio.

Todo el ceremonial, si bien mantiene su esencia prehispánica, ${ }^{28}$ pone en evidencia el papel que juegan los habitantes que viven en la capital, lo que se manifiesta en aspectos como los cambios en el banquete ceremonial. Según contaron los participantes, antes las familias preparaban con días de anticipación la comida que llevarían al ritual, que consistía en viandas típicas, tradicionales, como pachamanca, cordero, cuyes. Pero en el año 2016, cuando se participó en el ceremonial, lo que prepararon las familias eran comidas de la urbe metropolitana: arroz con pollo, arroz chaufa, estofado, papas a la huancaína, postres (como arroz con leche).

26 "Suni", cuarta región altitudinal, se ubica desde los 3500 hasta los $4000 \mathrm{msnm}$. Son quebradas estrechas constituidas por numerosos cursos de agua; y jalka o puna, quinta región natural, se eleva desde los 4000 hasta los $4800 \mathrm{msnm}$. Zona de mesetas y lagunas donde principian las nieves perpetuas; son páramos muy fríos de la alta cordillera de los Andes.

27 Años antes, la fiesta continuaba al día siguiente, cuando los que asumían los roles de las Parianas ofrecían una comida de ollucos.

28 En el interesante trabajo etnohistórico de Carlier (2008) en San Pedro de Huacos en la provincia de Canta, se ponen en evidencia las continuidades en los rituales de la limpieza de las acequias, desde el período prehispánico. 


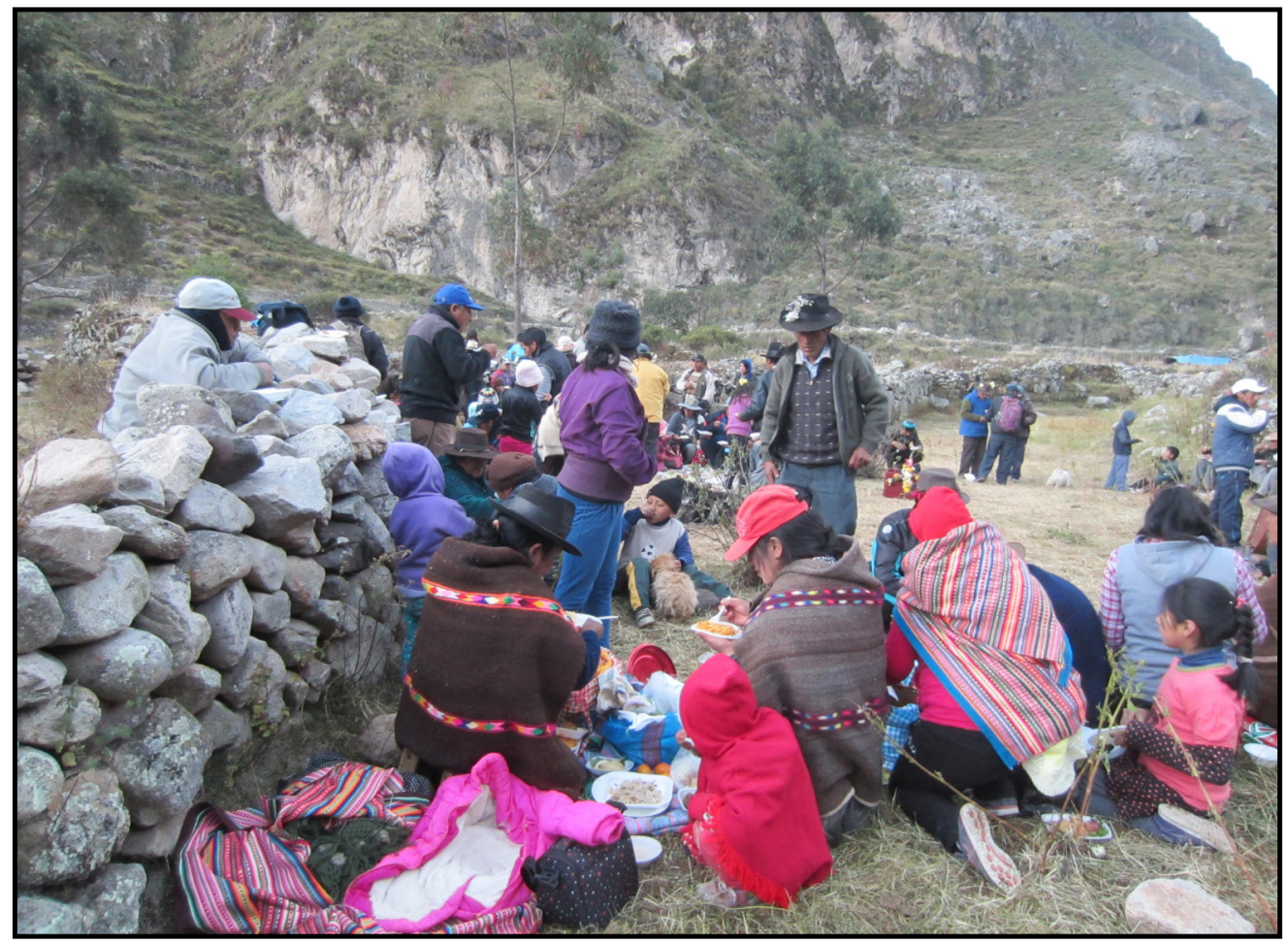

Figura 8. Banquete ceremonial. Fuente: Autores.

Un aspecto especialmente interesante de este ritual es el protagonismo de los personajes femeninos asociados con el agua y la agricultura: La Vieja, Riguacocha, la Cajera, ${ }^{29}$ los Parianes, etcétera. En la ceremonia del año 2014 la comunera viuda que asumía el rol de la Cajera cantaba a las huacas de las Tres Hermanas y les suplicó, en quechua y castellano, que envíen el agua para tener comida. Utilizó el mismo estribillo: Wui, wui, wui, que en el que relato del mito de Wa Kon y La Viuda.

"Riguacocha, mamita, / Riguacocha, señora. / Señora Riguacocha: bota bien tus agüitas, / para regar nuestra papita. / Wui, wui, wui. / Pumaquihuay, mamita, / señora del pueblo de Cullhuay, / Wui, wui. / Cerrito de La Viuda / subida y baja$\mathrm{da}, /$ rodeadito de tus pajonales, /(bis) rodeadito de tus pajonales. / Cuando subo a tu cumbre diviso el paisaje, / el paisaje de mi hermosa tierra [...]". ${ }^{30}$

Borea (2004, p. 157) recogió las siguientes canciones interpretadas en el canal de regadío Huaipa por la Cajera que "toca y anuncia a viva voz, en quechua y castellano":

"Añas para runkurun kullawalan. / Liklish, pupus hima pitah waqanki. / Wui, wui, wui"... ${ }^{31}$

29 Cajera, denominación que se da a la mujer viuda que canta acompañándose con un tamboril llamado tinya (cuya castellanización, caja, designa usualmente el conjunto de dos instrumentos, este de percusión y uno de viento, pues lo acompańa la flauta).

30 Canción interpretada por la comunera Delfina Cajavilca, en junio de 2014.

31 "Lluvia de zorrino o lluvia menuda, / que andas envolviendo / a la gaviota y al liken, / ¿¿dónde lloras? / 
"Puentecito Jochachaca / déjame pasar a Huaipa / para cosechar mis papitas, / ;ay, ayay, papa mahuay! / Puma Quihuay mamita, / Riguacocha seńora, / larga, pues, su agüita / para regar mi papita. / Wui, wui, wui”.

"Puentecito de Cullhuay / déjame pasar a mi comunidad / para hacer nuestras costumbres. / Wui, wui, wui. / ¡Viva señores apoderados!”.

La Cajera interpela a los pájaros, a la zorrilla y a la lluvia:

"Añas para runkurun kullawalan / 'Zorrillo, costal-lluvia, Ilukveme'. / Liklish, pupush (posiblemente pucapuca) imapitahwaqanki 'Gaviota, ¿por qué lloras'?”.

Es interesante observar precisamente de qué modo la Cajera realiza sus interpelaciones en quechua, un idioma que ha ido perdiendo importancia en las generaciones más jóvenes, que han convertido el castellano en la lengua cotidiana. Ahora nuevamente es el quechua el que juega un papel central. Este idioma facilita volver a los orígenes y restaurar los vínculos con los ancestros y los tiempos míticos originarios.

Como sostiene Gelles (1995, p. 385), este ritual les permite una larga catarsis comunal de dos días, asociada con la limpieza espiritual y física de los canales de agua. Los comuneros creían que el agua vendría con el "apaciguamiento ritual de las huacas mediante ofrendas". Ellos consideran al nevado y a las tres huacas como canales de comunicación entre los mundos de los humanos y sus dioses. Tal y como señala Platt (2003) en relación a los Macha:

Las divinidades subterráneas se invocan y se aplacan, pues se las considera fuentes de hostilidad, peste, accidentes y muerte; pero, al mismo tiempo, si se las alimenta y cuida, son promesa de renovación de la prosperidad y del deseo, así como fuente de regeneración de la vida individual y colectiva (p. 262).

\section{Interpretando las transformaciones socioambientales: de La Viuda al Cambio Global}

La profunda transformación en los aspectos biofísicos de los ecosistemas también está alterando la relación que "la gente tenía con el glaciar, el paisaje, su medio ambiente, los recursos naturales y entre ellos mismos" (Carey, 2014). Los comuneros consultados recrean la memoria de la imagen del glaciar que tenían sus abuelos o padres a inicios del siglo pasado: "Cuando veías a La Viuda, era una montaña cubierta de blanco, pero que ahora se está derritiendo. Mi madre me advertía entonces: cuando se acabe el blanco de La Viuda, será el fin del mundo, vendrá la sequia" (Doña Lucila, comunera, com. pers., Cullhuay, septiembre 2014).

Como vemos, los cullhuaínos vienen procesando de generación en generación que las fuerzas ambientales tienen su propia capacidad para actuar (Heyd, 2011). El tiempo se organiza de forma cíclica, tiene su principio y su fin. El final implica, en estas ontologías, un nuevo principio. Pese a ello, los comuneros pueden intervenir en este devenir a partir de acciones simbólicas, manteniendo un orden que siempre será provisorio. La deglaciación progresiva del nevado La Viuda, como otras transformaciones en el socioecosistema, se comienzan a vivir

Wui, wui, wui”. Tr. Fanel Guevara Guillén, agosto de 2018. 
por parte de los comuneros con una cierta impotencia, tal y como nos señalaron en diversas conversaciones. Los recursos, especialmente el agua, ya no son suyos, y por tanto la mitología y los rituales que ordenaban el espacio deben también resignificarse.

La pérdida de control sobre su territorio y sus recursos, los procesos migratorios que han desplazado a una parte de la comunidad a Lima y otras ciudades transforman la idea de "lo comunitario". Los rituales y mitos que ordenaban el mundo biosocial ya no son garantía suficiente para asegurar el equilibrio siempre inestable del socioecosistema. La ciencia ha sido también incorporada como parte de la mitología local. Por ejemplo, un taxista que nos trasladaba de Canta a Cullhuay nos explicaba que la causa que provoca el retroceso del glaciar (repitiendo los mensajes dados por "los expertos" en los medios de comunicación) “[...] era un problema de los paises altamente industrializados, que emitían mucho dióxido de carbono...". Las causas del retroceso del glaciar trascienden la comunidad, ya no dependen de su acción ni de sus vínculos ancestrales. De la misma forma que se les expropia los recursos, también se produce un proceso de expropiación de carácter discursivo.

Los mitos pierden fuerza en favor del discurso técnico-racional; de hecho, algunas de las leyendas narradas son conocidas por la gente mayor o bien recreadas fundamentalmente para consumo turístico, reelaborando sus aspectos más llamativos. Asistimos así a una cierta discontinuidad entre los mitos como base narrativa y los propios rituales que se siguen realizando. Este aspecto es muy interesante, ya que, si antes los rituales contribuían a articular la parte alta y baja del territorio, reforzando el vínculo con los componentes no humanos de la comunidad, actualmente gana peso el ritual como una forma de articulación de la comunidad que permanece en el pueblo y una parte muy significativa, con cada vez mayor influencia, que vive en Lima. Los territorios de referencia se transforman y con ello el propio sentido de los recursos con los que se vinculan.

La pérdida de sentido de alguno de los mitos, tanto como su progresivo desconocimiento por parte de la población, está vinculada, como señalamos, a su falta de eficacia. No solo se han transformado las formas organizativas que sustentan la comunidad, también lo ha hecho el medio. La Viuda, que se encuentra en Chuchún, ya no es visible, pero tampoco los bioindicadores que servían para predecir el clima, entre los que aparecen algunos de los "personajes" de los mitos, ya pueden dar cuenta de todos estos cambios. Tradicionalmente los pobladores han observado el comportamiento de animales, plantas y astros para vaticinar las variaciones climáticas que se traducirán en una buena, mala o regular crianza y cosecha. En la predicción del tiempo, al igual que en los mitos y rituales, el zorro jugaba un papel importante. La gente de Cullhuay predecía si tendrían un año lluvioso, seco o normal observando el comportamiento sexual de los zorros: "Cuando el rayo aparecía antes que las zorras entren en celo, es decir, se adelantaba a que el zorro entre en celo, es decir, se adelantaba a que el zorro montara a la zorra, vendrán las lluvias, año lluvioso, buen año. Y sucederá lo contrario cuando el zorro le gana al rayo, año seco" (conversación con un grupo de comuneros en Cullhuay, 10 de octubre, 2014).

Un proceso que se sintetiza en el refrán "Si gana el zorro, mal año; y si gana el trueno, buen año".

"Septiembre es el mes en que las zorras entran en celo, y son meses en que también se presentan rayos y truenos; es el tiempo de los denominados "repuntes" o lluvias "tempraneras" (conversación con un grupo de comuneros en Cullhuay, 10 de octubre, 2014). Sin embargo, nuestros informantes señalan que esto se producía en el pasado, y que ahora las lluvias no tienen la regularidad de antes. Tiene un carácter predictor, también, en el mismo mes de septiembre, el aspecto de la 
Luna: "En días de luna, allí observan la luna nueva. Cuando el cachito está equilibrado, no lloverá; en cambio, cuando está inclinado, viene la lluvia, el agua" (comunero de Cullhuay, agosto 2014). "Cuando en cuarto creciente la Luna está inclinada a la izquierda, viene cargada de lluvia, si al contrario está con manchas, no lloverá" (poblador de Cullhuay, agosto 2013).

En tales predicciones las lagunas jugaban también un papel importante: "La laguna Leoncocha avisaba si iba a llover, porque sonaba, y hasta ahora suena" (comunera de Cullhuay, agosto 2015).

Sin embargo, los bioindicadores pierden relevancia de la misma forma que el proceso de cambio, que se traduce en la desglaciación de La Viuda y la pérdida de biodiversidad, no puede ser interpretado únicamente con las narraciones tradicionales. Ellos observaban el comportamiento de los batracios, los escuchaban, pero "[ahora] algo que es diferente, es que ya no se ven sapos, estos han ido desapareciendo".

Los cóndores, si eran avistados en septiembre, predecían las lluvias: "Antes por estos sitios habia cóndores, cuando salian predecian lluvias" (comunero, Cullhuay agosto 2014). "En los meses de septiembre y octubre, hace más de 15 años atrás, por esta época empezaban los repuntes, o lluvias tempraneras, tres o cuatro días de lluvia, que luego se iban. Eran indicadores de buenas lluvias a partir de diciembre" (electricista, Cullhuay, septiembre 2014).

El nevado al que da nombre La Viuda anuncia de forma progresiva el final del mundo (de un ciclo). Ahora son las instancias nacionales e internacionales las legitimadas para actuar sobre un territorio en el que se redefinen las relaciones comunales de la misma forma que se desestructuran las relaciones con los seres no humanos. Nuevas interpretaciones sobre las transformaciones del medio, como el cambio climático y el cambio global, dan claves para la acción; sin embargo, cabría preguntarse en qué medida estas nuevas lecturas no suponen una desactivación de las lógicas locales, que ahora esperan los dictámenes científico-técnicos para poder actuar en un contexto en que sus mitos y rituales pierden eficacia. Una pregunta que nos lleva a un último interrogante, en el que consideramos que sería necesario profundizar en futuras investigaciones: ¿Las nuevas explicaciones desde perspectivas globalizadas no constituyen en algunos casos una forma de expropiación discursiva y de neocolonización de las poblaciones y saberes locales? ¿Las nuevas lecturas tecnocráticas sobre el agua no sustentan nuevos mitos vinculados con el mito central de la modernidad al que denominamos desarrollo?

Parece importante volver a repensar los espacios locales desde los saberes que los conformaron y de esta forma seguir posibilitando la diversidad socioambiental, la permanencia de los diversos mundos que conforman el pluriverso. Tal vez sea hora, como plantea Arturo Escobar (2014), de cambiar aquella máxima de pensar en global y actuar en lo local, invirtiendo los términos: pensar en local y actuar en global. Una reformulación que parte precisamente de unas especificidades que posibilitaron el mantenimiento de unos ecosistemas de incalculable valor a partir de largos procesos históricos, que dan cuenta precisamente de la existencia de una diversidad cultural que es indisociable de la diversidad socioambiental.

\section{Conclusiones}

La apropiación del espacio precisa de un proceso de traducción cultural. El espacio es una mera abstracción que requiere ser significado. La territorialización implica dar un sentido a los elementos con los que nos relacionamos. Los mitos y leyendas analizados ponen en evidencia una 
concepción que sobrepasa los esquemas parciales y segmentados del conocimiento occidental institucionalizado. La separación radical de la cultura y la naturaleza es una interpretación central en la ontología occidental. Ahora bien, desde otras ontologías el carácter binario que estructura nuestra forma de entender el sistema de relaciones con los diferentes seres no tiene sentido, tal y como sucedía y en buena medida continúa sucediendo en las culturas andinas.

Los mitos y rituales analizados nos muestran un mundo bio-socio-sobrenatural, en que priman los elementos considerados fundamentales para la supervivencia de la vida. Cada uno de los componentes es personalizado. No todas las piedras son iguales, como tampoco lo son las cuevas o las lagunas, porque no es solo el componente biofísico a través del que se puede definir "su carácter", tal y como se hace desde el discurso tecnocientífico. En este mundo se difumina no solo la tradicional dualidad cultura/naturaleza; también se difuminan las fronteras entre las clasificaciones científicas. Los animales comparten características humanas, como también sucede con los accidentes geográficos relevantes y, por supuesto, con el agua en sus múltiples formas. Esta humanización se produce también en relación con unas divinidades y espíritus, que además se confunden con elementos geográficos y climáticos. El medio, desde esta perspectiva, es el lugar donde viven los humanos, pero ellos no son una realidad al margen de los otros seres "naturales" y "sobrenaturales" con los que se relacionan, ya que conforman una misma comunidad.

La supervivencia de la comunidad depende en buena medida de las posibilidades de mantener este sistema de relaciones con las entidades bio-sobrenaturales. Y si en el seno de la comunidad humana la reciprocidad es un elemento central que permite garantizar su subsistencia, también lo es mantener esa relación de reciprocidad con los seres que propician la vida, como es el caso del agua o las lagunas y las entidades que están presentes en ellas. Así, la laguna es principio y fin, punto de partida y de llegada, desde una visión cíclica del tiempo. Hoy La Viuda sigue protegiendo la laguna de la que es propietaria, pero ya no es la única dueńa, como tampoco lo es la comunidad a la que pertenece. Ella era parte de la comunidad, la cuidaba, y cumplía un papel intermediario con los dioses y apus, de la misma forma que la comunidad cuida y exige a La Viuda a partir de un conjunto de rituales, tal y como reflejan sus mitos.

Accidentes geográficos, dioses, humanos y animales comparten un mismo relato. Así sucede, como hemos visto, en el relato de los gemelos Willca, hijos de dioses humanizados que son ayudados por ese Zorrillo capaz de enfrentarse y engañar a un dios tan maligno y fuerte como Wa Kon, provocando su muerte. En este mito esta articulación de seres, esta comunidad que trasciende el ámbito de lo humano, consigue amarrar y vencer al mal, aunque la amenaza sigue latente en el interior de la cueva, como un referente ético. Un referente que recuerda la vulnerabilidad de los humanos y la siempre potencial amenaza de que Wa Kon consiga despertar y escapar de su encierro. Los mitos integran todos los elementos significativos del territorio en esta comunidad bio-socio-sobrenatural. Como hemos visto en la leyenda de las Tres Hermanas, el mito ordena el territorio, lo personaliza e indica las obligaciones de los comuneros no solo entre ellos, sino también con las otras entidades integradas en lo comunitario.

Los mitos y los rituales narrados muestran una forma singular no solo de entender el medio, sino también de actuar sobre el mismo. A través de los discursos y rituales se mantienen las necesarias relaciones de reciprocidad a diversos niveles. Es precisamente a través de estos rituales como los comuneros actualizan el mito y, sobre todo, cumplen sus obligaciones entre ellos y con los componentes no humanos con los que conviven, como lo pudimos comprobar en las ofrendas al agua. 
La celebración del agua supone en buena medida el desorden, que es representado en el cambio de papeles de los hombres que se transforman en animales y en mujeres. El orden social se restaura a partir de realizar el ritual, de la misma forma que se restauran las relaciones con los recursos personificados y divinizados, que permiten la vida. Se articula la población que está fuera el resto del año con los comuneros que permanecen en la localidad, se limpian acequias, se bautizan niños, se establecen alianzas de compadrazgo, se realizan faenas comunales, los comuneros intercambian comida y se da de comer al agua... El "desorden" que impera durante la celebración impone un nuevo orden, una renovación necesaria reafirmada en las relaciones de reciprocidad.

Ahora bien, los mitos recopilados son cada vez menos conocidos por las nuevas generaciones. El clima se reinterpreta en clave global, como también sucede con unos recursos que han pasado a depender de instancias supralocales. Los bioindicadores que servían para predecir el clima, en los que se encuentran algunos de los personajes de los mitos, son cada vez menores y menos eficaces en el orden imaginario en el que se articulaban formas de organización comunal, recursos, animales, accidentes geográficos... Las nuevas interpretaciones contribuyen a desactivar las vinculaciones de esta comunidad bio-socio-sobrenatural.

El proceso de expropiación material va acompañado, como no podría ser de otra forma, de un proceso de expropiación discursiva, que traduce los recursos en unas claves que condicionan la acción local a los dictámenes de "los expertos" y a las decisiones tomadas en Lima, que es en último término donde se decide sobre las formas de gestión. La desglaciación de la cordillera de La Viuda tal vez sea un indicador del cambio climático, como se señala desde el discurso científico-técnico, o tal vez el final del mundo, como nos comentaba una de las informantes, o quizás las dos cosas al mismo tiempo. Pero cada una de ambas interpretaciones tiene consecuencias diferentes. El cambio global implica una acción global, mediada por el discurso de los expertos, que despersonaliza al nevado y lo sustrae de la lógica del "dar-recibir-devolver"; "descomunaliza" el medio. El fin del mundo anunciado en el mito local nos enfrenta a un inicio de un nuevo ciclo.

El paisaje se fue transformando a partir de la acción del Estado y la desaparición de algunos bioindicadores, al mismo tiempo que el discurso tecnocrático se reprodujo desde las instituciones escolares. Esto ha hecho perder fuerza al papel personificado de toda una serie de componentes (como el propio nevado). Las nuevas generaciones ya no sienten la obligación de la reciprocidad con los elementos no humanos, y los componentes míticos forman parte del recuerdo para los más jóvenes, como forman parte del recuerdo las procesiones que realizaban sus padres para propiciar la lluvia. De la misma forma, se han ido simplificando los rituales, que siguen jugando un papel importante en cuanto que fuerzan al retorno a aquellos miembros de la comunidad que están afuera, pero que van perdiendo fuerza como forma de articular un territorio que actualmente se ha ampliado. Los comuneros hoy están también en Lima y en otras localidades, desde donde recrean, de otra manera, a través de otras acciones ritualizadas, sus relaciones con los comuneros que permanecen en la localidad y también con un medio que ya no forma parte de su cotidianidad. Estos hechos explican, por un lado, la vigencia de un ritual como la Champería, en cuanto que posibilita en la práctica la contestación de la comunidad a las lógicas globales, pero también en cuanto obliga a los comuneros no residentes a renovar sus vínculos.

Ahora bien, asistimos a una progresiva simplificación del ritual. Algunas investigaciones muestran cómo este tipo de rituales se ha ido reduciendo en su duración, pero también en su 
significación. El quechua se ha transformado, de ser el lenguaje cotidiano, en un referente importante desde el punto de vista simbólico, pero ya es "extraordinario" (en favor del castellano). De la misma forma, las significaciones conocidas por los mayores y la articulación con los mitos locales de este ritual cada vez son menos conocidas por la gente joven, formada en otra realidad discursiva. Tal como el nevado tutelar va perdiendo, poco a poco, su nieve creída eterna, los rituales pierden su significación y adquieren nuevos sentidos, renovando una comunidad que por unos días recuerda su carácter unitario en torno a un recurso central para la vida como es el agua.

\section{Referencias citadas}

Abercrombie, T. A. (1986). The Politics of Sacrifice: An Aymara Cosmology in Action. Tesis Doctor of Philosophy. University of Chicago, USA.

Agrawal, A. (1997). Community in conservation: beyond enchantment and disenchantment. Gainesville, FL: Conservation \& Development Forum (CDF) (Discussion Paper).

Alberti, G. y Mayer, E. (Comps.). (1974). Reciprocidad e intercambio en los Andes peruanos. Lima: Instituto de Estudios Peruanos.

Albó, X. (2011). Suma Qamaña=Convivir bien. ¿Cómo medirlo? En Farah, I. H. y Vasapollo, L. ( Coords.). Vivir bien: ¿Paradigma no capitalista? (pp. 133-144). La Paz: CIDES-UMSA - Sapienza Universitá di Roma - Oxfam.

Arce, R. (2011). Sistematización del diálogo regional de adaptación y de aprovechamiento de aguas de la agricultura al cambio climático en los Andes. Lima: GTZ. Recuperado de: www.programaaacc.pe/docs/referencia/ Vision_Regional_ACC.pdf

Arguedas, J. M. (1986). Las comunidades de España y Perú. Madrid: Cultura Hispánica (original publicado en 1968).

Autoridad Nacional del Agua, ANA (2014). Inventario nacional de glaciares y lagunas. Recuperado de: repositorio.ana.gob.pe/handle/ANA/199

Azogue Guaraca, A. A. (2016). Maneras de ser comunidad. Gazeta de Antropología, 32(1), artículo 06 [http://hdl.handle.net/10481/43159]

Bauman, Z. (2003). Comunidad, en busca de seguridad en un mundo hostil. Madrid: Siglo XXI.

Belotti, F. (2014). Entre bien común y buen vivir. Afinidades a distancia. Íconos: Revista de Ciencias Sociales, 48(1), 41-54. doi.org/10.17141/iconos.48.2014.1208

Bolados, P. y Babidge, S. (2017). Ritualidad y extractivismo. La limpia de canales y las disputas por el agua en el salar de Atacama, norte de Chile. Estudios Atacameños. Arqueología y Antropología Surandinas, 54, 201-216.

Bollier, D. y Helfricht, S. (2013). Patterns of commoning. The Commons Strategies Group Overture. Recuperado de: http://patternsofcommoning.org/overture.

Borea, G. (2004). Tras los pasos del Parián en el evento y en el tiempo: Imágenes y representaciones en la sierra de Lima. Antropológica, 22, 151-178. 
Borea, G. (2008). Nuevas generaciones y continuidad ritual. En Romero, R. (Ed.). Fiesta en los Andes: Ritos, música y danzas del Perú (pp. 72-101). Lima: PUCP Fondo Editorial, Instituto de Etnomusicología.

Brachetti, A. (2005). El año en fiestas. La convivencia con los dioses en los Andes del Perú. Madrid: Ministerio de Cultura.

Cancino, I. y Valcárcel, M. (2000). Institucionalidad y riego. El valle del Chillón. Lima, Debate Agrario, $31,77-97$.

Cánepa Koch, G. (2001). Identidades representadas: Performance, experiencia y memoria en los Andes. Lima: PUCP - Instituto Riva Agüero - Centro de Etnomusicología Andina.

Carey, M. (2014). Glaciares, cambio climático y desastres naturales. Ciencia y sociedad en el Perú. Revista de Ciencia Sociales, 42(17), 190-192.

Carlier, A. (2008). Le nettoyage rituel des canaux d'irrigation d'une communauté de la cordillère de Lima (province de Canta, Pérou): une approche ethnohistorique, Bulletin de l'Institut Français d'Études Andines, 37(2), 351-374. doi: 10.4000/bifea.314

Carrión Cachot, R. (2005 [1955]). El culto al agua en el antiguo Perú. La paccha, elemento cultural panandino. Revista del Museo Nacional de Antropología y Arqueología, 2(2), 50-140.

Choque, C. y Pizarro, E. (2013). Identidades, contigüidades y rupturas en el culto al agua y a los cerros en Socorama, una comunidad andina de los Altos de Arica. Estudios Atacameños. Arqueología y Antropología Surandinas, 45, 55-74. Recuperado de: https://revistas.ucn.cl/index.php/estudios-atacamenos/article/ view/57

Coca, A. (2008). Los camperos. Territorios, usos sociales y percepciones en un espacio natural andaluz. Sevilla: Fundación Blas Infante.

Coca, P. A. y Quintero M. V. (2006). Los de fuera claman por la naturaleza ¿Qué reclaman los de dentro? En Valcuende del Río, J. M. y Cardia, L. M. Territorialización, Medio Ambiente y Desarrollo en Brasil y en España (pp. 319-348). Rio Branco, Acre, Brasil: Editora da Universidade Federal do Acre.

Cortés, J. A. (2014). A natural life: neo-rurals and the power of everyday practices in protected areas. Journal of Political Ecology, 21, 493-515.

Cruikshank, J. (2005). Do Glaciers Listen? Local Knowledge, Colonial Encounters and Social Imagination. Vancouver, BC: University of British Columbia Press.

Damonte, G. (2016). Transformación de la representatividad política local en los contextos extractivos a gran escala en los Andes peruanos. En Damonte, G. y Glave, M. (Eds.). (2016). Industrias extractivas y desarrollo rural territorial en los Andes peruanos: los dilemas de la representación política y la capacidad de gestión para la descentralización (pp. 19-58). Lima: GRADE.

Descola, P. (2005). Par-delà nature et culture. París: Gallimard.

Descola, P. (2009). Human natures. Social Anthropology/Anthropologie Sociale, 17(2), 145-157.

Descola, P. (2011). Más allá de la naturaleza y la cultura. En Montenegro Martínez, L. (Ed.). Cultura y naturaleza. Aproximaciones a propósito del bicentenario de la independencia de Colombia (pp. 75-98). Bogotá: Alcaldía Mayor de Bogotá - Jardín Botánico José Celestino Mutis. 
Diez, H. A. (Ed.). (2012). Tensiones y transformaciones en comunidades campesinas. Lima: CISEPA PUC, $284 \mathrm{pp}$.

Diez, H. A. (2017). Organización y poder en comunidades, rondas campesinas y municipios. En ¿Qué sabemos de las comunidades campesinas? (pp. 107-152). Lima: Grupo Alppa.

Durand, L. (2005). Los mitos y la conservación ambiental. Revista Líder, 3(10), 215-225.

Durkheim, E. (1982). Las formas elementales de la vida religiosa. Madrid: Akal.

Escobar, A. (2014). Sentipensar la tierra. Nuevas lecturas sobre desarrollo, territorio y diferencia. Medellín: Ediciones Universidad Autónoma Latinoamericana (UNAULA).

Farfán, L. C. (2002). El simbolismo en torno al agua en la comunidad de Huaros, Canta. Bulletin de l'Institut Français d'Études Andines, 31(1), 115-142 (Lima, IFEA).

García, G. (2012). Lloren las ranas, casen las aguas, conténganse los vientos. Rituales para llamar la lluvia en el centro y sur andino. Revista Española de Antropologia Americana, 42(1), 145-168.

Gelles, P. (1984). Agua, faenas y organización comunal: el caso de San Pedro de Casta. Tesis de doctorado. Pontificia Universidad Católica del Perú, Lima.

Gelles, P. (1995). Etnohidrología, "desarrollo" y política cultural en la sierra peruana. En González Alcantud, J. y Malpica, A. (Ed.). El agua, mitos, ritos y realidades (pp. 375-400). Barcelona: Antropos.

Goloubinoff, M., Katz, E. y Lammel, A. (Ed.). (1997). Antropología del clima en el mundo hispanoamericano. Quito: Abya-Yala.

Golte, J. y De La Cadena, M. (1983). La codeterminación de la organización social andina. Allpanchis, 19(22), 7-34.

Guillet, D. (1995). Revisión, riego y organización humana: una visión desde los Andes. En González Alcantud, J. y Malpica, A. (Eds.) El agua, mitos, ritos y realidades (pp. 308-328). Barcelona: Anthropos .

Hardt, M. y Negri, A. (2011). Commonwealth: el Proyecto de una Revolución del Común. Madrid: Akal.

Heyd, T. (2010). Ruedas medicinales como observatorios del Cambio Climático. Revista del Círculo Hermenéutico $(\mathrm{CH}), 8,12-21$.

Heyd, T. (2011). Pensar la relación entre la cultura y cambio climático. En Ulloa, A. (Ed.). Perspectivas culturales del clima (pp. 17-30). Bogotá: Universidad Nacional de Colombia - ILSA.

Hidrandina (1988). Inventario de glaciares del Perú. Lima: CONCYTEC. Recuperado de: http://ponce.sdsu. edu/INVENTARIO_GLACIARES_ANA.pdf

Instituto Nacional de Estadística e Informática - INEI (2018). Directorio Nacional de Centros Poblados. Censos Nacionales 2017: XII de Población, VII de Vivienda y III de Comunidades Indígenas. Lima.

Laval, C. y Dardot, P. (2014). Común: Ensayo sobre la revolución en el siglo XXI. Barcelona: Gedisa.

Llanque, C. D. (2003). Pacha; vivencia andina: diálogo y celebración cósmica. Revista Electrónica Volveré, 2(7). Recuperado de: http://www.iecta.cl/revistas/volvere_7/articulos.htm

Mattei, U. (2013). Bienes comunes: un manifiesto. Madrid: Trotta. 
Montesinos, L. y Campanera, M. (2017). Formas de vida, usos y apropiación de recursos. Propuestas para el estudio de los comunes contemporáneos. Revista de Antropología Social, 26(2), 193-216.

Mossbrucker, H. (1990). La economia campesina y el concepto de "comunidad": un enfoque critico. Lima: IEP.

Ostrom, E. (2011). El gobierno de los bienes comunes. La evolución de las instituciones de acción colectiva. México, FCE (1a edición en inglés, 1990).

Pálsson, G. (1996). Human-environmental relations: orientalism, paternalism and communalism- En Descola, P. y Pálsson, G. (Eds.). Nature and Society: Anthropological Perspectives (pp. 63-81). Londres: Routledge.

Pinedo, G. D. (2006). Acción colectiva en los Andes. Comunidad y conservación en la cordillera Huayhuash. Tesis de Licenciatura en Antropología. Universidad Nacional Mayor de San Marcos, Lima.

Platt, T. (2003). Los guerreros de Cristo. Cofradías, misa solar y guerra regenerativa en una parroquia andina (siglos XVIII a XX). En Vaca, L. (Ed.). Fiesta, juego y ocio en la historia (pp. 253-320). Madrid: Ediciones Universidad de Salamanca.

Pulgar Vidal, J. (2014). Las ocho regiones naturales. Lima: INTE - PUCP.

Ráez, M. (2002). Jerarquía y autoridad comunal. Los varayos y la Fiesta del Agua de la comunidad campesina de Lachaqui, Canta. En Cánepa, G. (Ed.). Identidades representadas (pp. 331-368). Lima: Fondo Editorial PUCP.

Rappaport, R. (1987). Cerdos para los antepasados. El ritual en la ecología en un pueblo de Nueva Guinea. México: Siglo XXI (1a edición en inglés, 1968).

Rösing, I. (1996). Rituales para llamar la lluvia. Segundo ciclo de Ankari: Rituales colectivos de la región kallawaya en los Andes bolivianos. Estudios Kallawaya, 6 (Traducción de Mundo Anakari 5, 1993/2006) Cochabamba/La Paz: Los Amigos del Libro.

RostworowskI, M. (1978). Señorios indigenas de Lima y Canta. Lima: IEP.

Ruiz, B. E. (2012). Socioecosistemas y resiliencia socio-ecológica. Una aproximación compleja al medio ambiente. En Ruiz Ballesteros, E. y Solana Ruiz, J. L. (Ed.). Complejidad y ciencias sociales (pp. 295-330). Sevilla: Universidad Internacional de Andalucía.

Santamarina, B. (2005). La patrimonialización de la naturaleza: figuras y discursos. En Pascual, J. J. y Florido, D. (Eds.). ¿Protegiendo los recursos? Áreas protegidas, poblaciones locales y sostenibilidad (pp. 9-44). Sevilla: Fundación El Monte.

Sherbondy, J. (1995). El agua: ideología y poder de los incas. En González Alcantud, J. y Malpica, A. (Ed.). El agua, mitos, ritos y realidades (pp. 87-102). Barcelona: Anthropos.

Subirats, J. (2013). Bienes comunes y contemporaneidad. Releyendo a Polanyi. Ecología Politica, 45, $22-29$.

Tello, J. C. y Miranda, P. (1923). Wallallo: ceremonias gentílicas en la región cisandina del Perú, distrito arqueológico de Casta. Inka I, 2, 475-549.

Ulloa, A. (Ed.). (2011). Perspectivas culturales del clima. Bogotá: Universidad Nacional de Colombia - ILSA.

Urrutia, J., Remy, M. I. y Burneo, M. L. (2019). Comunidades campesinas y nativas en el contexto neoliberal peruano. Lima: IEP y CEPES. 
Valcuende del Río, J. M. (1998). Fronteras, territorios e identificaciones colectivas. Sevilla: Fundación Blas Infante.

Valcuende del Río, J. M. (2003). Proyecto Docente e Investigador para el Acceso a Concurso de Plaza de Cuerpo Docente Universitario. (inédito).

Valcuende del Río, J. M. (2012). La patrimonialización de los espacios naturales: lógicas de poder y estrategias de resistencia. En Santamarina, B. (Coord.). Geopoliticas patrimoniales (pp. 55-76). Valencia: Germania.

Valcuende del Río, J. M., Quintero, V. y Cortés, J. A. (2011). Naturalezas discursivas en espacios protegidos. AIBR. Revista de Antropología Iberoamericana, 6(1), 27-56. doi: 10.11156/aibr.060103

Valcuende del Río, J. M. y Ruiz-Ballesteros, E. (2019). Trapped in nature. Concepts of humanity in the naturalization of protected areas. Journal of Political Ecology, 26, 184-201.

Van Der Berg, H. (1989). La tierra no da asi nomás: los ritos agrícolas en la religión de los aymaras-cristianos. Amsterdam: CEDLA.

Varas, M. N. (2017). Comunidad y clima. Transformaciones en la cuenca alta del río Chillón. Tesis doctoral. Universidad Pablo de Olavide, Sevilla.

Villar, C. P. (1933). Folklore de la provincia de Canta (en el departamento de Lima). El mito "Wakon y los willka” referente al culto indígena de la cordillera de La Viuda. Revista del Museo Nacional, 2(2), 161-179. 